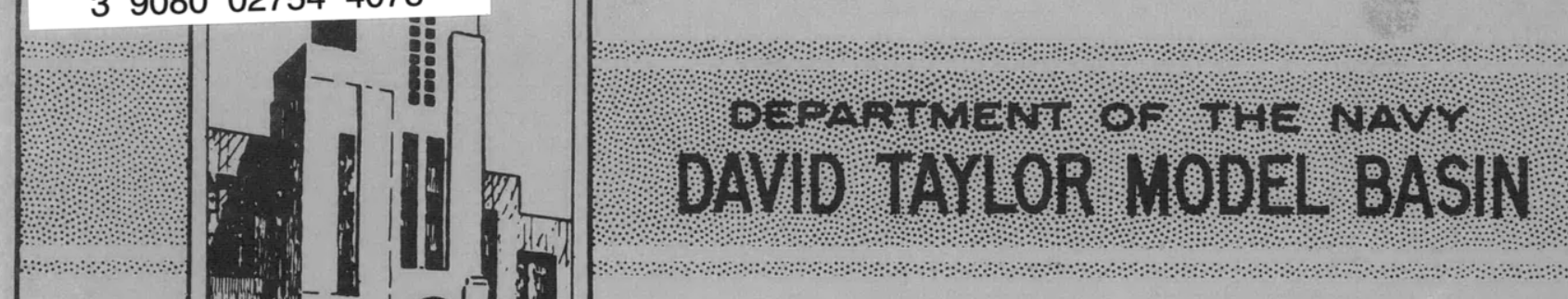

HYDROMECHANICS

THE RESPONSE OF SHIPS TO

UNDERWATER EXPLOSIONS

○

AEROOYNAMICS
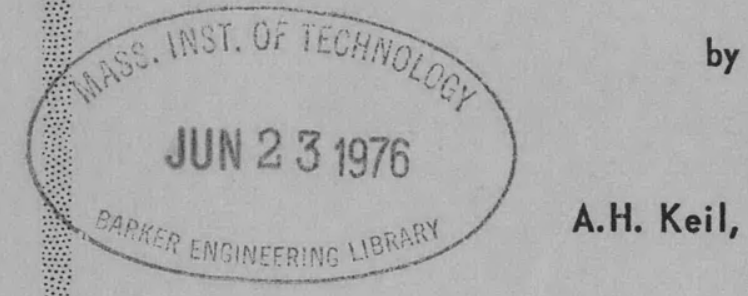

b

AEROONNAMISS

○

STRUCTURAL

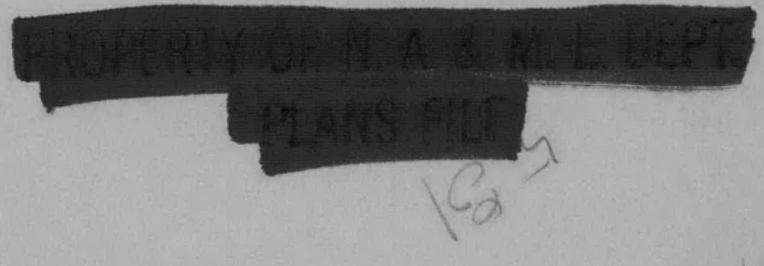

MECHANICS

A.H. Keil, Ph.D.

o

APPLIED MATHEMATICS

STRUCTURAL MECHANICS LABORATORY RESEARCH AND DEVELOPMENT REPORT 


\title{
THE RESPONSE OF SHIPS TO
}

\section{UNDERWATER EXPLOSIONS}

\author{
by
}

\section{A.H. Keil, Ph.D.}

Reprint of Paper Presented at The Annual Meeting

Society of Naval Architects and Marine Engineers

16-17 November 1961. New York, N.Y. 


\title{
The Response of Ships to Underwater Explosions
}

\author{
By A. H. Keil, ${ }^{1}$ Member
}

\begin{abstract}
The various phases of an underwater explosion are described in the paper. Nomograms are given for characteristic parameters of the shock wave and the bubble pulsation. Possible effects of the water surface and the sea bottom are discussed. Characteristic ship-response phases are also reviewed and explained. They are demonstrated by actual examples of hull response and hull damage. The shipboard shock environment to which any installation aboard a ship is subjected is presented, and typical cases of shock damage are shown. The significance of the study of ship response to underwater explosions is reviewed. Generalization of the few controlled explosion tests against ships becomes possible by application to loading and response theories. The foundation is thus laid for increasing the combat reliability of ships and their endurance under attack.
\end{abstract}

EFFECTs of underwater explosions on ships have been studied ever since it was realized that explosions under water could be accomplished. Thus a new field in naval warfare was opened. Systematic explosion tests against ships started in the 1860's, and the first tests conducted in the United States by General H. L. Abbott were reported in $1881[1]^{2}$. Since these early beginnings extensive test programs were conducted by all major naval powers prior to World War I. The name of Admiral Stocker stands out in the United States effort. The results of these studies are reflected in the protection measures designed into the hulls of those ships which fought in World War I. This war brought home the importance of the torpedo and floating or anchored mines in naval warfare, and thus established the need for better protection of ships against the effects of contact hits with these weapons.

The interval between World War I and World War II saw systematic efforts by all major naval powers to develop and improve the design of special hull arrangements to reduce the effect of

\footnotetext{
${ }^{1}$ Technical Director, Structural Mechanics Laboratory, David Taylor Model Basin, Washington, D. C.

- Numbers in brackets designate References at the end of the paper.

For presentation at the Annual Meeting, New York, N. Y., November 16-17, 1961, of The SocietY OF NAval ARChITECTS AND MARINE ENGINERRS.
}

such explosions. Ship sections and, mainly, models of ship sections of various designs were tested under different severities of attack. Based on damage inspections and performance comparison, conclusions were drawn on the effectiveness of design changes and improved design features. This approach was very effective and resulted in the side-protection systems of the Midway class in the United States, of the Hood in Great Britain, and of the Tirpitz and Bismarck in Germany, to mention a few examples.

This progress was based mainly on the applications of new steels, structural arrangements, and concentrated research efforts during and since World War I, which have led to the recognition of the phenomena associated with underwater explosions. The measurement of the expansion of the gas bubble was reported by Ramsauer [2], and the theoretical treatment of the early expansion is due to Lamb [3]. Butterworth [4], in 1923 extended Lamb's treatment to include the effect of external (hydrostatic) pressure and found that this gas bubble must oscillate Pressure measurements also were made with ingenious mechanical means, and the state of this art at the end of World War I is reported by Hilliar. [5].

The advent of World War II brought the threats of standoff explosion of ground mines activated by proximity fuses, of more powerful 
torpedo warheads, and of attacks from the air. The use of noncontact explosions and the associated widespread shock damage to machinery and shipboard equipment suddenly emphasized the need to know all the effects associated with explosions under water.

World War II thus brought about a great intensification of the research on underwater explosions, with parallel efforts especially in the United States, Great Britain, and Germany. Simultaneously, major strides were made to provide better protection of capital ships and to overcome the shock problem.

At the end of World War II the majority of the original papers which were not subjected to security restrictions were compiled jointly by the United States Navy and the British Navy in the three volumes of "Underwater Explosions Research" issued in 1950 by the Office of Naval Research, U. S. Navy [6]. A systematic presentation of the physical effects associated with underwater explosions was given in 1948 by Cole [7], but his book contains essentially no information on the damage process.

Intensive research on the phenomena of underwater explosions has continued since World War II especially within the U. S. Navy. The first nuclear-weapons test under water, Test Baker of Operation Crossroads, demonstrated that for such applications of nuclear weapons, a knowledge of the effects of underwater explosions is also required [8]. This test gave further impetus to this type of research.

The rapid development since World War II in the understanding of the response of ship structures to underwater explosions is due mainly to the persistent research and development efforts of the U. S. Navy's Bureau of Ships to assure the greatest potential for survival of the ships of our Navy in a wartime environment. The results of the past 20 years of this research are contained in hundreds of reports which required security classification because of the immediate military conclusions. Only a few papers dealing with effects of underwater explosions on ships are available in the literature. King [9], for example, gives a broad approach to the ship protection aspects in ship design, and Hollyer [10] treats one phase, the deformation of plane plates under shock-wave loading, in the simplest theoretical approach and draws several conclusions with respect to ship design. Snay $[11,12]$ describes the hydrodynamics of underwater explosions and some phases of the ship response from the standpoint of the hydromechanic effects of the explosion.

The purpose of this paper is to extract from the wealth of information available the most significant results of interest for the response of ships to underwater explosions and to present them in a coherent fashion. This purpose is best served by answering the following three questions:

1 What is the sequence of events which lead to damage to ship structures?

2 How can significant response phases be analyzed?

3 How can the research results be applied?

The paper is divided into four parts. Part 1 gives a brief description of the phenomena associated with underwater explosions; Part 2 discusses the development and analysis of hull damage; Part 3 discusses the principal types of shock damage to machinery and equipment; ' and Part 4 presents the applications of the results to naval architecture.

\section{The Underwater Explosion}

\section{Sequence of Events}

The sudden energy release associated with the explosion of a conventional high explosive or a nuclear weapon leads to the formation of a superheated, highly compressed gas bubble and

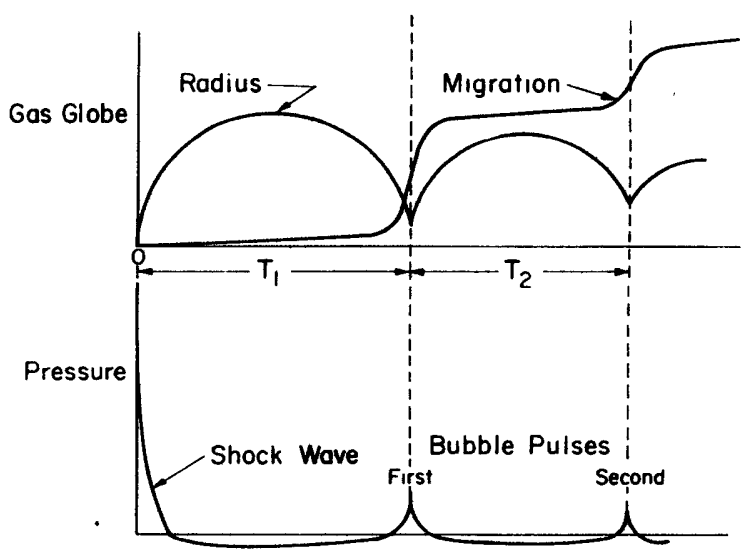

Fig. 1 History of underwater explosion events, schematic

the generation of a shock wave in the surrounding water. The exponentially decaying pressure wave propagates as a spherical pressure wave originally at speeds much faster than the speed of sound in water. The propagation velocity drops rapidly to the sound velocity (approximately $5000 \mathrm{fps}$ ). In the meantime the gas bubble begins to expand in size while the gas pressure in the bubble gradually decreases. This bubble expansion overshoots the equilibrium condition between hydrostatic pressure and gas pressure. After reaching 


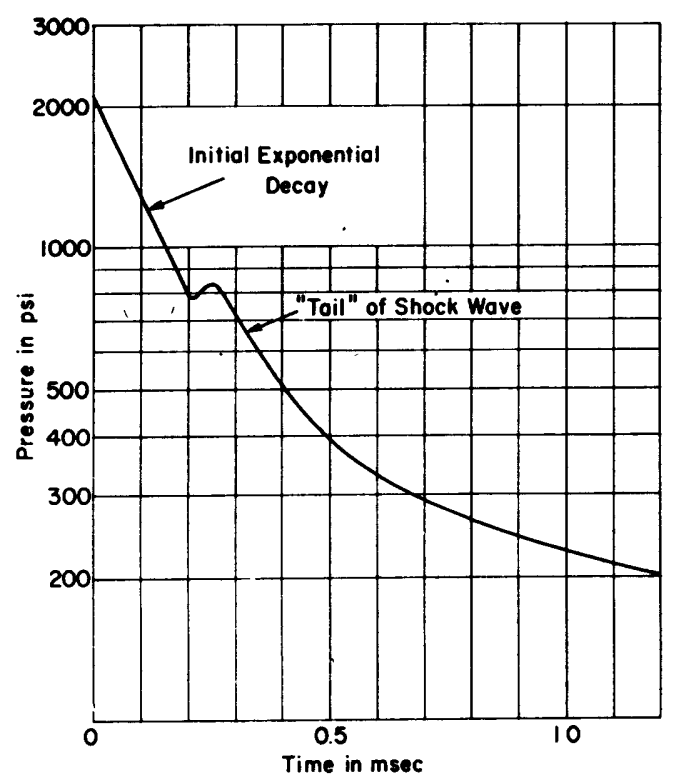

Fig. 2 Shock wave from 19-lb TNT at $20 \mathrm{ft}$

a maximum radius with a minimum pressure considerably below the hydrostatic pressure, the bubble contracts again, slowly at first but with a final rapid collapse to a minimum radius. Because of the generation of a large pressure in the bubble during this stage the bubble begins to expand again, and several other cycles may follow. At each minimum, that is, each recompression, additional pressure pulses are emitted which are not shock waves and which become weaker with each oscillation. However, they still represent important dynamic loads for ship structures. The first such bubble pulse can have a peak pressure of 10 to 15 per cent of the shock-wave peak pressare. During this pulsation process, the bubble migrates upward because of the influence of gravity, with the maximum migration occurring during the minima, Fig. 1.

\section{The Shock Wave}

The underwater shock wave generated by the explosion is superimposed on the hydrostatic pressure. The pressure history at a fixed location starts with an instantaneous pressure increase to a peak pressure $p_{0}$ (in less than $10^{-7} \mathrm{sec}$ ) followed by a decay which in its initial portion is usually approximated by an exponential function, Fig. 2 . Thus

$$
p(t)=p_{0} e^{-t / \theta}
$$

with $\theta$ as decay time, valid for $0 \leq t \leq \theta$.

The shock wave and the following pressure wave generated by the explosion can be described just as well by the pressure distribution in the water at fixed times, if the propagation velocity is known. This velocity depends on the peak pressure of the shock wave and is, for pressures up to $10,000 \mathrm{psi}$, described by the linear approximation

$$
\begin{array}{cc}
C \stackrel{\sim}{=} c\left(1+6 \times 10^{-6} p_{0}\right) & p<10000 p 5 \mathrm{c} \\
\left(p_{0} \text { in } \mathrm{psi}\right) & \sim 5,000 \neq \mathrm{ps}
\end{array}
$$

For all practical purposes in the discussion of ship damage this velocity is approximately 5000 fps. The pressure distribution behind a plane shock front is given by

$$
p(x)=p_{0} e^{-x / c \theta}
$$

which is a good approximation for the spherical shock wave at large distances from the explosion.

The peak pressure as well as the decay constant depends on the size of the explosive charge and the standoff from this charge at which the pressure is measured. For trinitrotoluene (TNT)

$$
\begin{gathered}
p_{c}=21,600\left(\frac{W^{1 / 3}}{R}\right)^{1.13}, \mathrm{psi} \\
\theta=0.058 W^{1 / 3}\left(\frac{W^{1 / 3}}{\mathrm{R}}\right)^{-0.22}, \text { millisec }
\end{gathered}
$$

with charge weight $W$ expressed in pounds of TNT and the standoff $R$ measured in feet. These formulas apply to any size of charge, from a few grains to nuclear weapons, exploded at any depth, and describe the shock wave properly except in the immediate vicinity of the explosive charge, where the peak pressure is higher than the formula predicts. During the initial propagation of the shock wave, that is, in the very highpressure region, much energy is lost in the shock front due to heat losses (non-adiabatic temperature increase near the shock front). These losses rapidly become smaller as the pressure drops to several thousand psi but are never negligible as indicated by the variation of pressure with $R^{-1.13}$; acoustic propagation with no loss would provide a variation with $R^{-1}$.

As the shock wave passes a fixed location and subjects the liquid at this point to a transient pressure $p(t)$, the liquid is simultaneously subjected to a flow with a velocity $v(t)$ in the direction of the wave which is related to the transient pressure:

$$
p(t)=\rho c v(t)
$$

with $\rho$ density of the water and $c$ the propagation velocity (sound velocity in water). For convenient conversion, $100 \mathrm{psi}$ corresponds to 1.5 fps flow or particle velocity.

A correction due tó spherical flow is necessary, and then the flow velocity becomes 


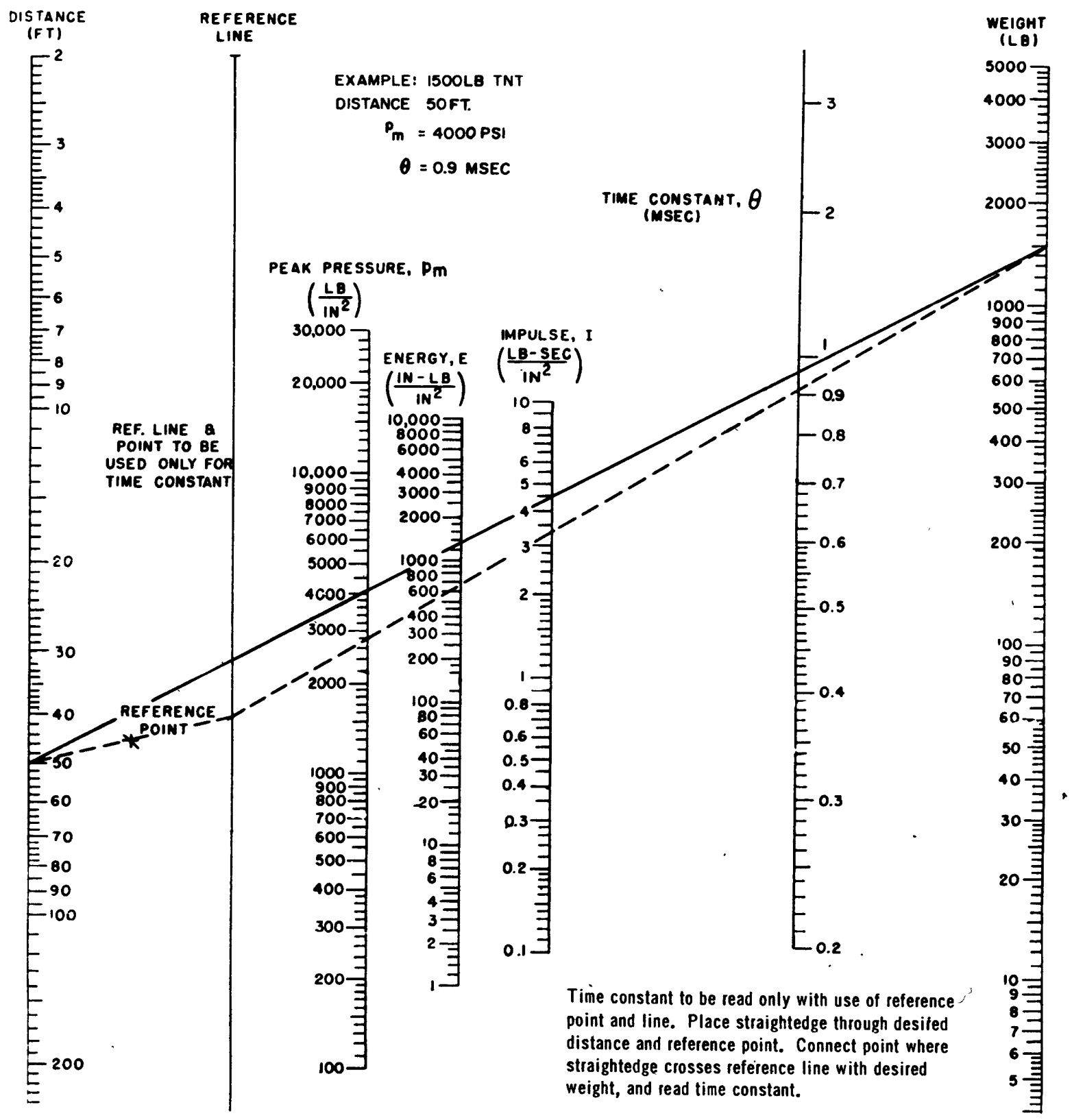

Fig. 3 Underwater shock-wave parameters for TNT (made available by U. S. Naval Ordnance Laboratory, White Oak, Md.)

$$
v(t)=\frac{p(t)}{\rho c}+\frac{1}{\rho R} \int_{0}^{t} p(t) d t
$$

The first term is the previously discussed velocity and the correction term is called the "afterflow" term. The afterflow term becomes significant in the close vicinity of the explosion, and also for large time intervals.

The energy in the shock wave of the explosion consists of two equal components, one pertaining to the compression in the water, the other to the associated flow. The shock-wave energy density $E_{\mathrm{sh}}$ (that is, shock-wave energy per square inch of wave front) for a plane shock wave is

$$
E_{\mathrm{Bh}}=\frac{1}{\rho c} \int_{0}^{\infty} p^{2}(t) d t
$$

For a fully exponential shock wave

$$
E_{\mathrm{sh}}=\frac{1}{\rho c} p_{0}^{2} \theta
$$

The Response of Ships to Underwater Explosions 


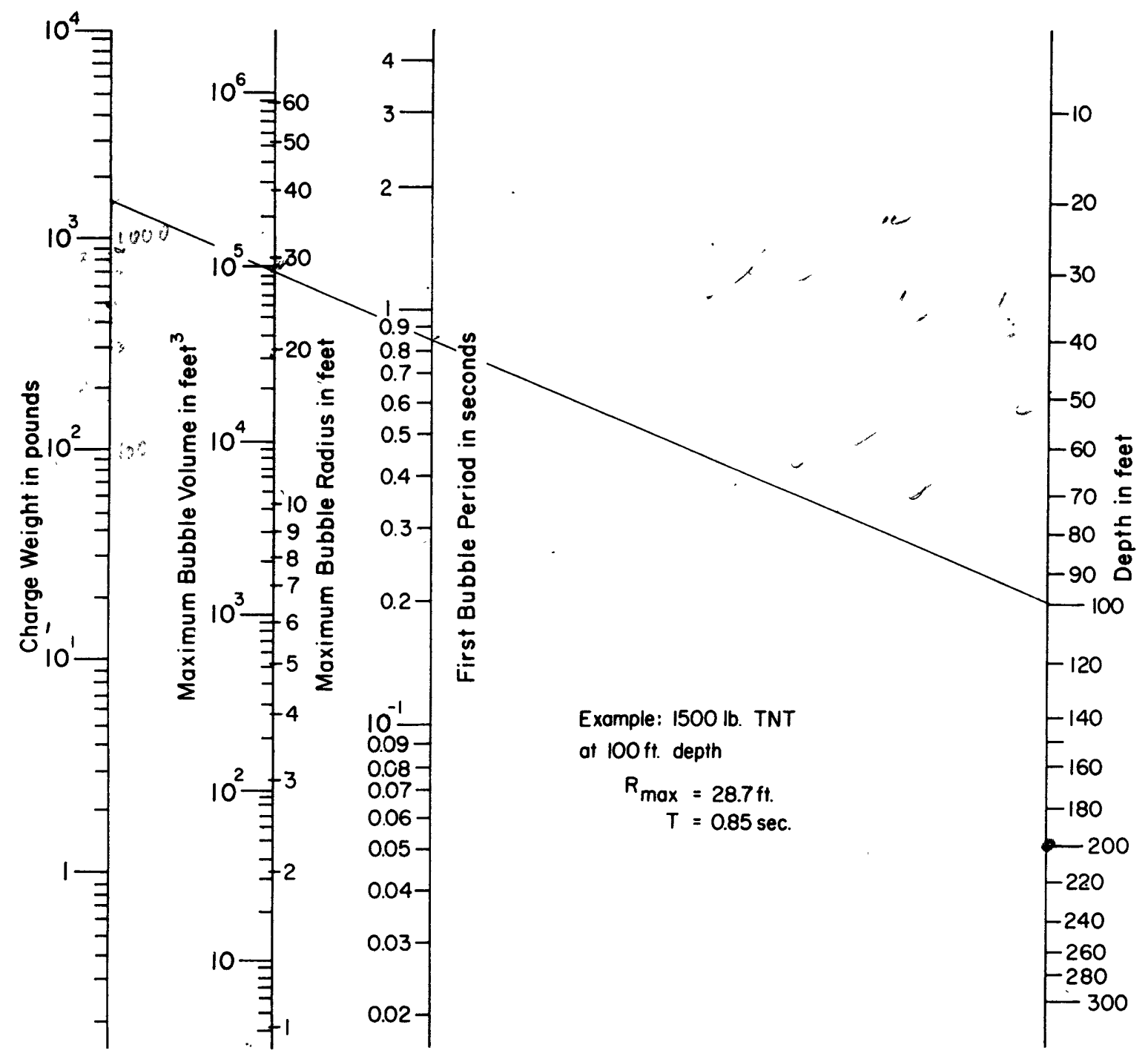

Fig. 4 Nomogram for maximum radius and time of first bubble pulsation

Using the numerical relations between the charge weight and the shock-wave parameters, this energy density at a distance $R$ from the explosion of $W$ lb of TNT is approximately

$$
E_{\text {sh }}=200 W / R^{2} \mathrm{ft}-1 \mathrm{~b} \text { per in. }{ }^{2}
$$

- For convenience, the nomogram, Fig. 3 , is provided for determining $p_{0}, \theta$, and $E_{\mathrm{sh}}$ easily.

\section{The Gas Bubble}

The gas bubble generated by the explosion is nearly spherical during the initial expansion and contraction. The two characteristic parameters are the maximum radius $R_{\max }$, reached during the first pulsation and the duration $T$ of the first pulsation (from explosion to the first following minimum, Fig. 1). Both vary with the size of the explosive charge ( $W$ lb TNT) and the depth $(D \mathrm{ft})$ at which the explosion occurs:

$$
\begin{aligned}
R_{\mathrm{max}} & =12.8\left(\frac{W}{Z_{0}}\right)^{1 / 2} \cdot \mathrm{ft} & \text { acadius of gas buo } \\
T & =4.36 \frac{W^{1 / 3}}{Z_{0}^{5 / 6}} \mathrm{sec} & \text { dination of prisc }
\end{aligned}
$$

where $Z_{0}=D+33$ represents the total static pressure at the location of the explosive. A nomogram, Fig. 4, makes it possible to determine both quantities readily as well as the maximum volume of the gas bubble.

For convenience in applying the theory of the bubble pulsation [13,14] given in Appendix 1, 


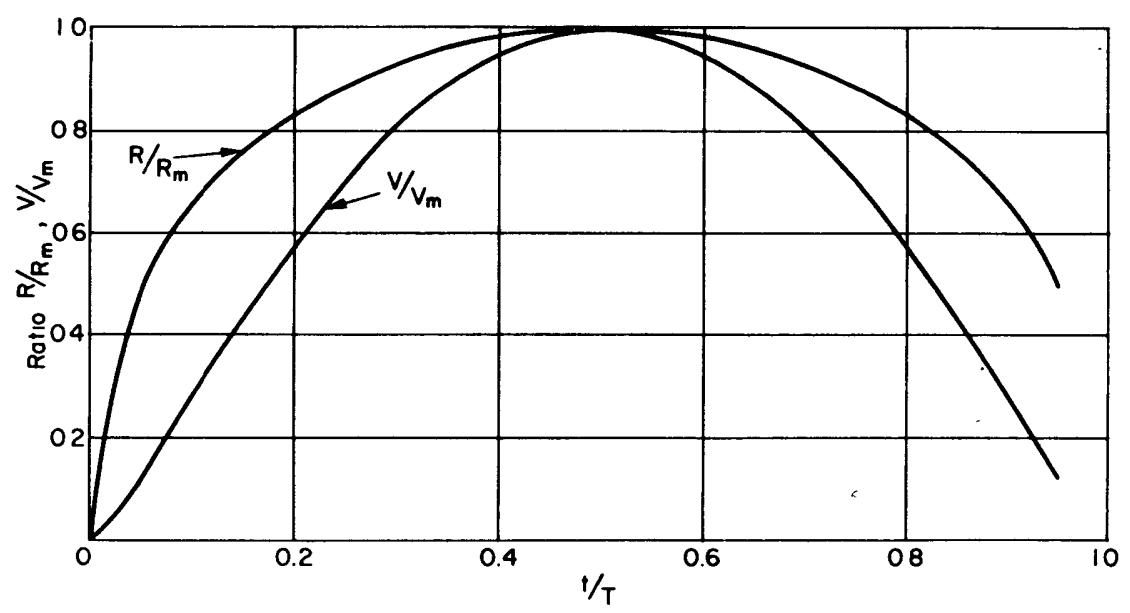

Fig. 5 Normalized curves for first bubble pulsations

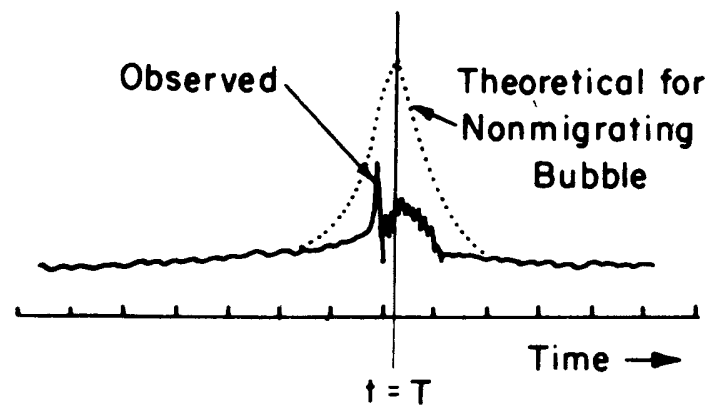

Fig. 6 Shape of first bubble pulse

nondimensional plots for bubble radius and bubble volume versus time are given for the first pulsation of the gas bubble in Fig. 5 .

The bubble at the end of the first pulsation expands again but loses energy due to the emission of a bubble pulse near the minimum and due to migration. This pulse, propagating again at sound velocity, does not have the steep front of the shock wave but is rather symmetrical, Fig. 6 [12]. The peak pressure measured at a fixed standoff from the explosion is usually about 10 to 15 per cent of the shock-wave peak pressure, but many factors can reduce this peak pressure (especially the large migration for the gas bubble of large explosive charges). Nevertheless, this bubble-pulse loading can impose serious localized loads on a ship hull, since the bubble is also subjected to the gravity field. This causes the bubble to migrate toward the water surface.

Superimposed is the hydrodynamic mechanism. of bubble collapse, Fig. 7. The bubbles of large explosions such as mines or torpedoes lose their symmetry during the first oscillations because

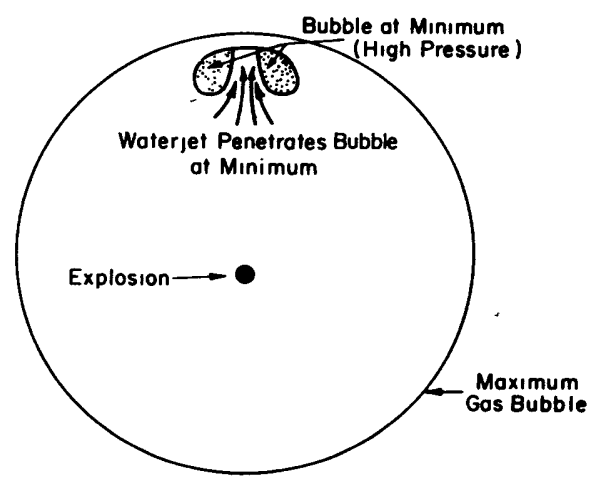

Fig. 7 Mechanism of bubble collapse

of the difference in hydrostatic pressure between the bottom and the top of the bubble. When the bubble contracts toward the minimum, the water near the lowest part of the bubble moves much faster toward the center than the water on the sides, which, in turn, moves faster than the water at the top. This leads to a huge, highvelocity water jet penetrating the bubble which, at that time, forms a torus. This development is well described and documented by Snay [12]. This water jet, together with the high-pressure field surrounding the bubble at that instant, is extremely efficient in producing damage.

\section{Energy Balance}

The energy balance of an underwater explosion, disregarding gravity migration, is given in Table 1.

The energy balance applied to the case of 1500 $\mathrm{lb}$ of TNT is given in Table 2 , with $1060 \mathrm{cal} / \mathrm{gm}$ used as the total energy release of a TNT explosion. 
Table 1 Energy Balance of an Underwater Explosion

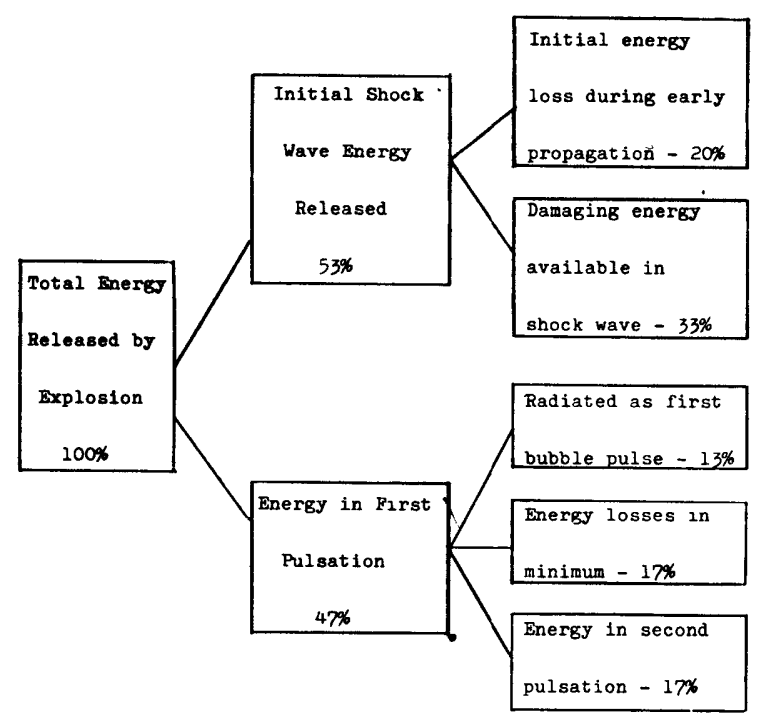

Table 2 Energy Distribution for a 1500 pound TNT Underwater Explosion

\begin{tabular}{|c|c|c|}
\hline Total energy release. . . . & $\begin{array}{l}. \mathrm{Kg} \mathrm{cal} \\
72 \times 10^{5}\end{array}$ & $\stackrel{\text { Ft }-1 b}{22 \times 10^{3}}$ \\
\hline $\begin{array}{l}\text { Shock-wave energy (minus } \\
\text { initial losses) }\end{array}$ & & \\
\hline First bubble pulsation..... & - & $10.4 \times 10^{8}$ \\
\hline First bubble pulse, radiated & - & $29 \times 10^{8}$ \\
\hline
\end{tabular}

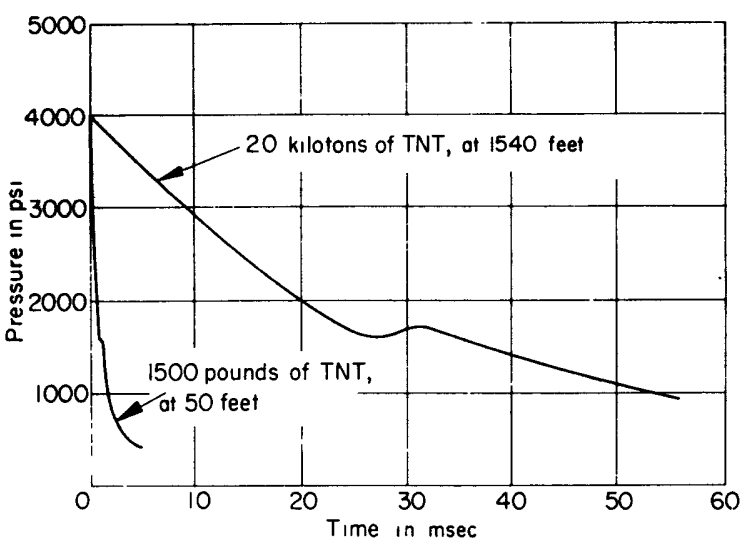

Fig. 8 Shock wave of $1500-1 b$ TNT and 20 kilotons of TNT (at distances for equal peak pressure)

Table 3 Typical Examples of Maximum Radius and Pulsation Time for Underwater Explosions

$\begin{array}{lcc} & 20 \mathrm{kt} \text { TNT } & 1500 \mathrm{lb} \text { TNT } \\ & 2000 \mathrm{ft} \text { deep } & 100 \mathrm{ft} \mathrm{deep} \\ R_{\max }(\mathrm{ft}) & 245 & 28.7 \\ T(\mathrm{sec}) & 2.6 & 0.85\end{array}$

\section{Examples}

Application of the results to two specific cases will further clarify the preceding discussion: a mine of $1500 \mathrm{lb}$ of TNT exploding at a depth of $100 \mathrm{ft}$ in water of much greater depth, and a nuclear weapon of $20 \mathrm{kt}$ of TNT exploding 2000 $\mathrm{ft}$ below the surface in the deep ocean. The

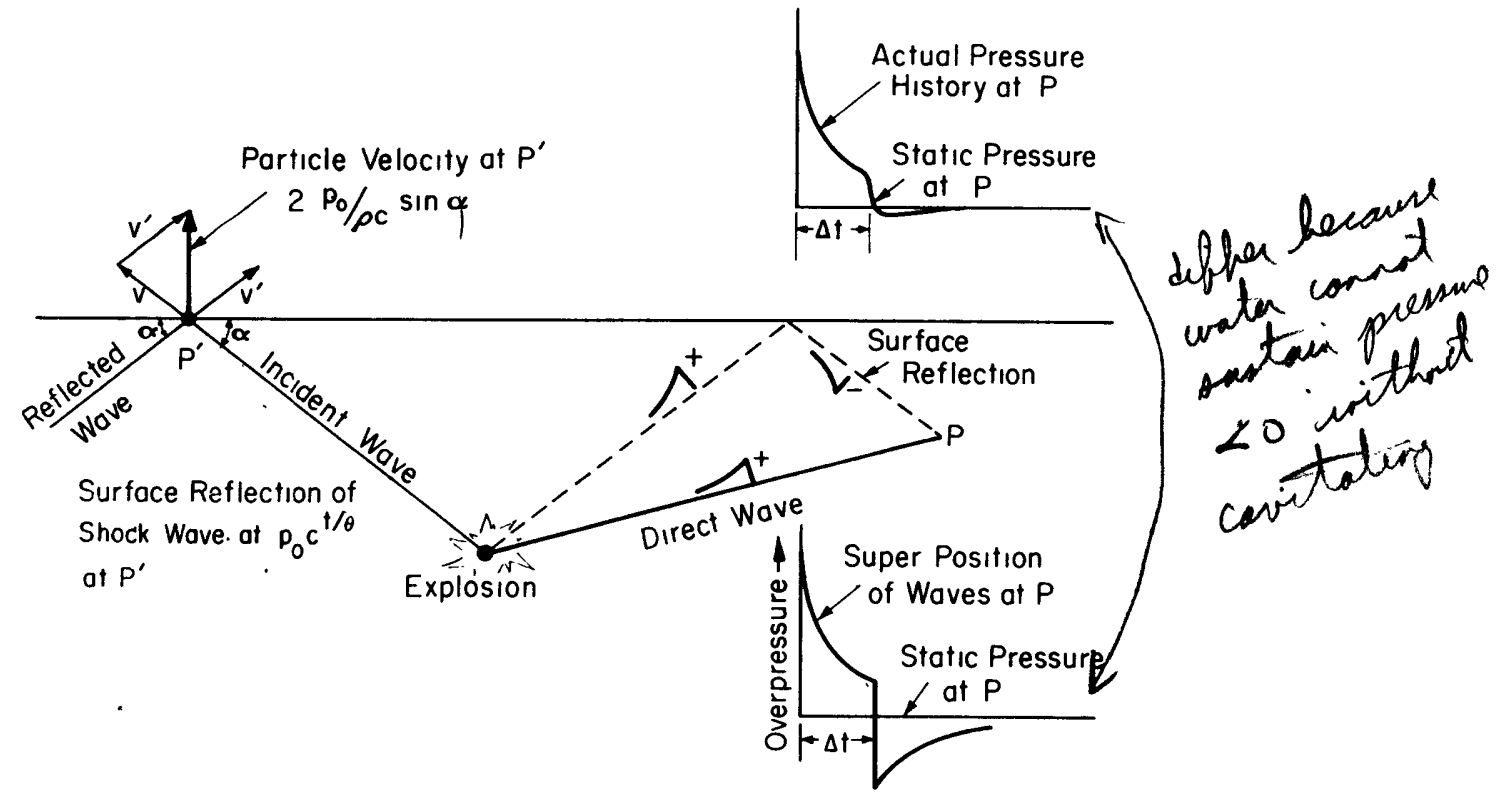

Fig. 9 Reflection of shock wave at water surface 


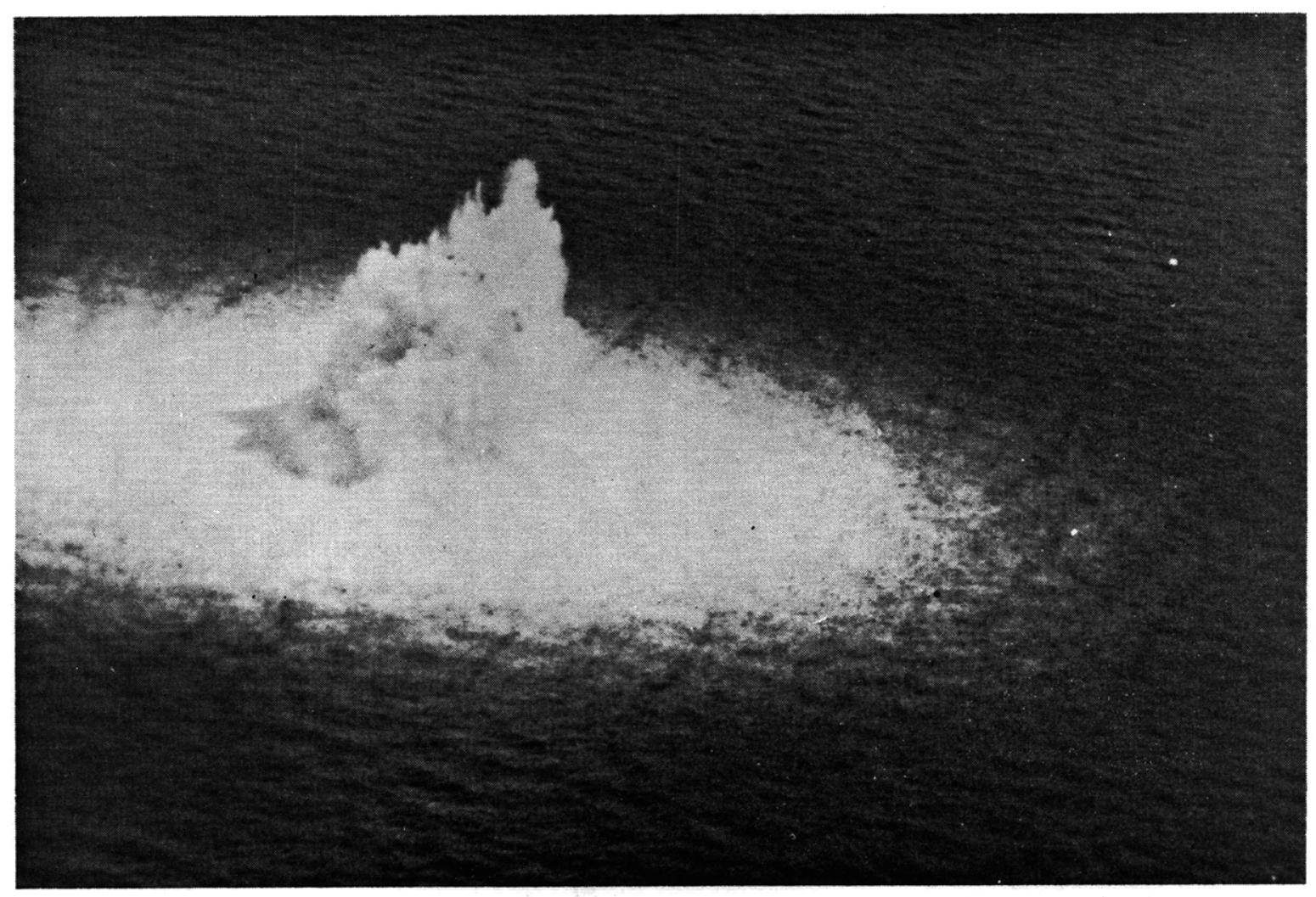

Fig. 10 Spray dome and plume of an underwater explosion

shock wave for both cases is plotted in Fig. 8, with the standoff chosen so that the peak pressures are equal. The pulsation time and the maximum radius is tabulated for both cases in Table 3.

\section{Influence of Surface and Sea Bed}

The vicinity of the water surface has an effect on the explosion phenomena. When the shock wave with peak pressure $p_{0}$ reaches the water surface, it is reflected as a tension wave; the water surface receives a vertical velocity, as shown in Fig. 9, and a brilliantly white spray dome develops. The water just underneath the water surface cavitates as a result of the reflected wave and forms a bulk cavitation region $[7,12]$. For the pressure history at any location, the arrival of the surface-reflected wave means a cancellation of the shock-wave pressure for that instant on, an effect called "surface cutoff." For a depth $D$ of a charge, a location at a depth $d$, and a standoff (horizontal) $R$, from this charge, this cutoff occurs approximately at

$$
\Delta t=\frac{0.4 D d}{R} \text { msec } \quad(\text { all lengtns in } \mathrm{ft})
$$

A reflection of the shock wave on the ocean bottom can also occur; in this case the reflected wave is a compression wave.

The jets forming during the bubble minima can reach the water surface, penetrate the spray, and form picturesque plumes; Fig. 10. If the explosion occurs at rather shallow submergence, the explosion gases may blow out into the atmosphere soon after the explosion, and a bubble pulsation cannot form.

An explosion occurring at the bottom of the sea cannot naturally form a spherical bubble, but must develop a hemispherical gas bubble sitting on the bottom. This bubble can, however, due to the gravity field, break away from the bottom and then go through a pulsation process with associated upward migration [12].

\section{Principal Types of Hull Damage and Response}

\section{Response and Damage to Side Shell}

A ship exposed to attacks by underwater weapons may suffer many types and various degrees of damage resulting from the loads generated by the explosion of such weapons. The following 


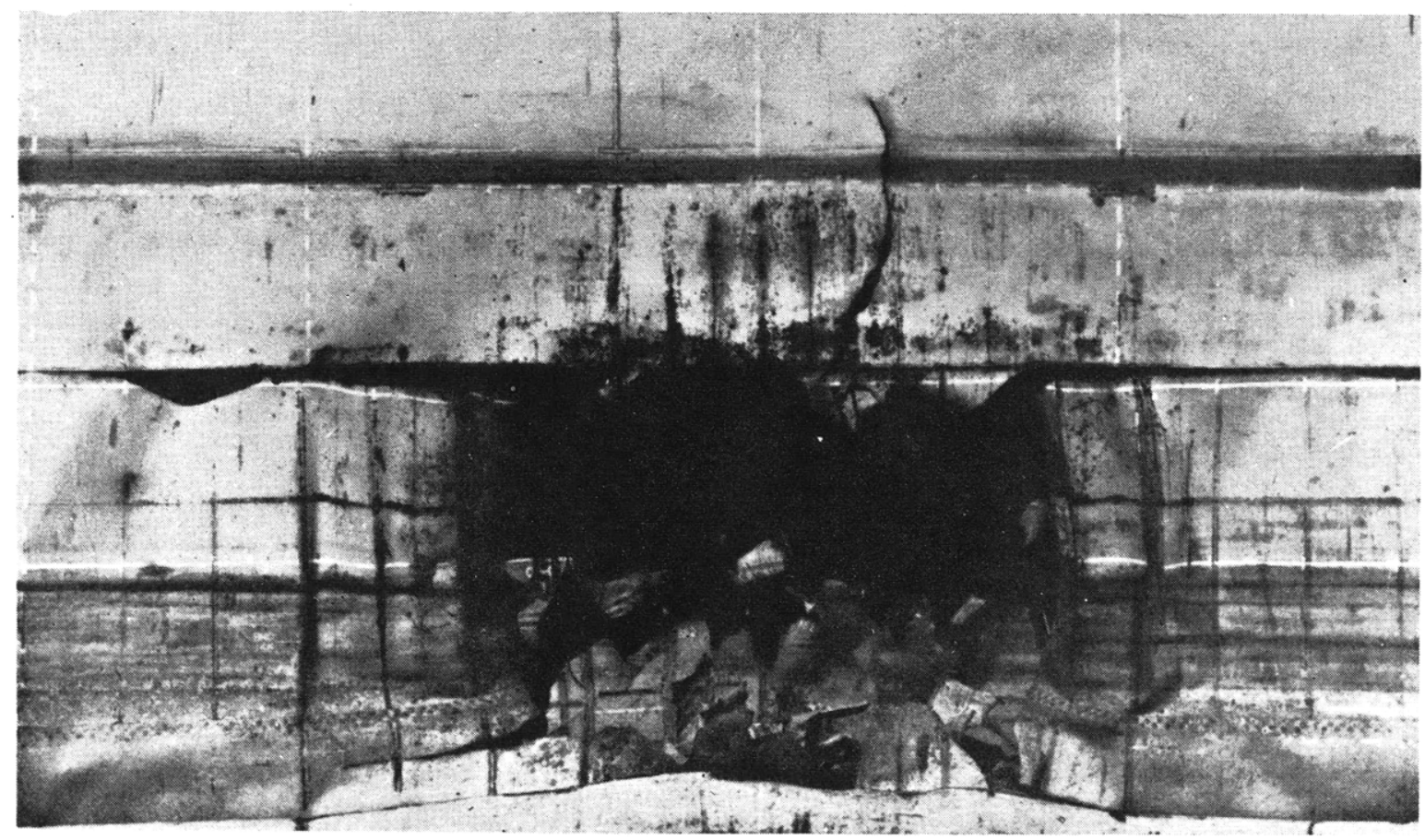

Fig. 11 Hole in side of ship from contact explosion

factual description highlights the, various damage patterns.

A torpedo or a mine, exploding in contact with the shell of a ship, tears a large hole of about 30 to $50 \mathrm{ft}$ in the fore-and-aft direction into the ship's hull. The rupture of the bulkheads close to the point of attack is due to direct exposure to the explosion forces, or to deformation caused in the bulkhead by hull deformation. Fragmentation of the shell occurs in the area of impact and causes a hazard not only to installation, machinery, and personnel, but to bulkheads which may be pierced. The large hole in the shell, Fig. 11, causes the compartment that was hit to flood rapidly. Flooding will spread rapidly into adjacent compartments if the bulkheads are damaged severely. Although the damage in the immediate attack area is devastating (the extent depending on the size of the charge), it does not extend far, either inboard, Fig./2, or in the fore-and-aft direction.

For an explosion of the weapon in the proximity of the ship, the degree of damage depends not only on the payload of the warhead of the weapon but also on the standoff of the explosion from the hull and the orientation with respect to the ship. In general, it is the practice to distinguish between explosions under bottom and explosions off the side, since the gas bubble, due to its migration may contribute greatly to the extent and severity of damage if the explosion occurs under the ship. Standard terminology is indicated in Fig. 13.

If the explosion occurs close to the side shell, the rupture pattern is similar to the contact explosion, Fig. 12. As the standoff increases, the "hull splitting" standoff is reached. This limiting standoff separates the range in which the shell is ruptured and the range in which severe hull deformation occurs without rupture. For further increases in standoff, the amount of deformation decreases continuously until a standoff is reached which separates the range where plastic hull deformation occurs from the range where the hull response is strictly elastic.

A typical example of hull damage is shown in Fig. 14. 'The side shell of a ship's model has deformed slightly between the stiffeners (which cannot be seen in the figure), and has suffered an overall deformation limited by the double bottom and the second deck. In the longitudinal direction, bulkheads partly confined the extent of damage but suffered severe deformation near the side shell. The L-stiffeners were tilted as were most of the supporting brackets. The realism of this damage pattern observed on a model has been confirmed by the deformations actually observed on ships damaged by noncontact explosions.

The deformation and load history of the side 


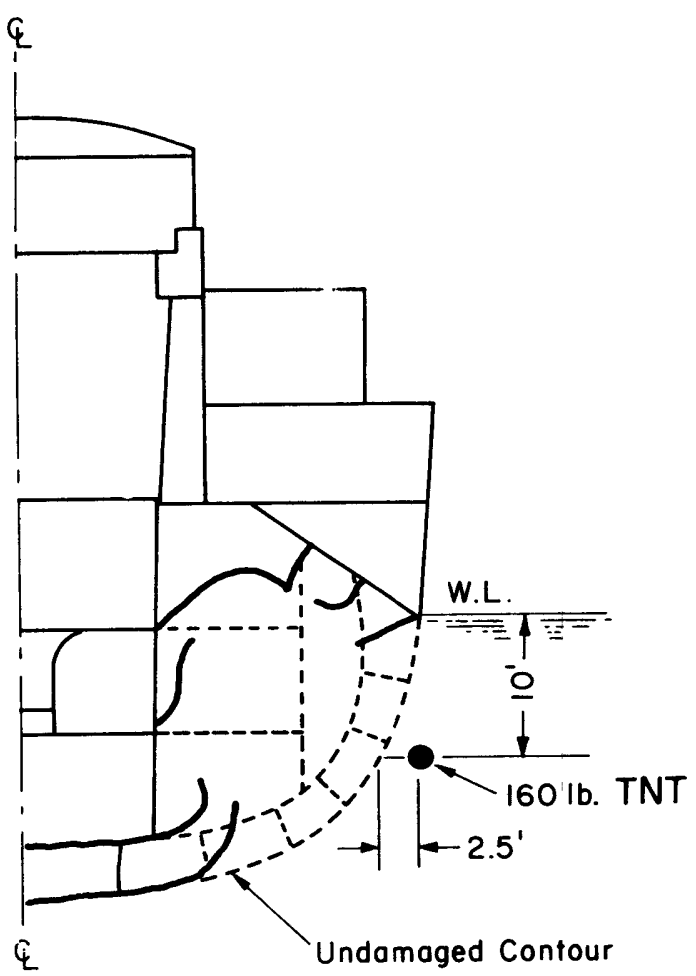

Fig. 12 Extent of internal damage from simulated torpedo explosion

shell of a merchant ship (as derived from a model test) demonstrate the salient features of the transient loading and the dynamic response of the ship structure to the shock wave generated by an explosion off the center of the hull plating of a compartment. The initial loading phase is illustrated in Fig. 15, which gives the pressure history measured simultaheously at the side shell and at a location 45 in. outboard. Both records are plotted on the same time scale, and an idea of the pressure distribution in the water in front of the hull can be obtained. The initial record of the 45-in. stand-off gage shows the incident shock wave with its initial decay. Later the reflected wave, which has a very sharp cutoff, comes back from the hull. In the middle of the time interval between shock-wave peak and peak of the reflected wave, the pressure arrives at the hull. Here the fast pressure drop in the reflected wave and the much slower decay of the incident wave superimpose to produce the fast cutoff of the loading, occurring within $270 \mathrm{msec}$. The velocity which the hull plating has picked up at this moment is the initial kickoff velocity since, at this instant, the loading drops to zero, associated with cavitation at or near the plate surface. The stiffeners, acting as an initial restraint to the

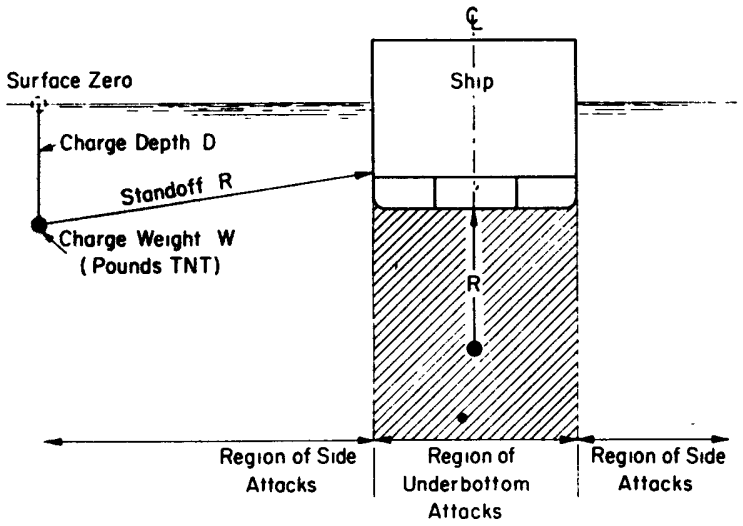

Fig. 13 Noncontact explosions

hull plating, are accelerated as the hull dishes between the stiffeners, and a uniform velocity of the stiffener-plate combination develops rapidly (Appendix 2).

The deflection history for the midpoint of the stiffened hull of a compartment, Fig. 16, shows the initial takeoff of the plate-stiffener combination due to its kickoff velocity. As the deflection develops, the stiffened hull slows down until a "reloading phase," resulting from closure of the cavitation space outboard of the hull, causes a new impulse (35 msec after shock-wave incidence) which slightly increases the deflection. In this specific case, the later loading phases contributed little to the final deflection. Their contribution can, however, be significantly higher for other attack conditions.

This reloading, which occurs much earlier than the bubble pulse, has been studied in detail $[11,15]$. Cavitation not only occurs at the hull but also in the water outboard of the hull and leaves a velocity distribution in the cavitated region which extends outward from the hull over a limited distance. This cavitated water will pile up gradually against the hull as the plate decelerates, thus making additional shock-wave energy available for damage.

The boundary of cavitation that remains after the cavitated water has piled up against the hull has been subjected to the flow field of the expanding gas bubble. The water flow which thus develops corresponds to the flow into a cavity. This motion causes a new loading which can be calculated adequately by using the Lamb approximation for the early bubble expansion $[3,15]$.

The adequacy of Schauer's theory [15] of this "reloading" is demonstrated by the fact that the observed second kickoff of the hull coincides with the moment when the water jet hits the center of the deflected hull configuration. Due to this 


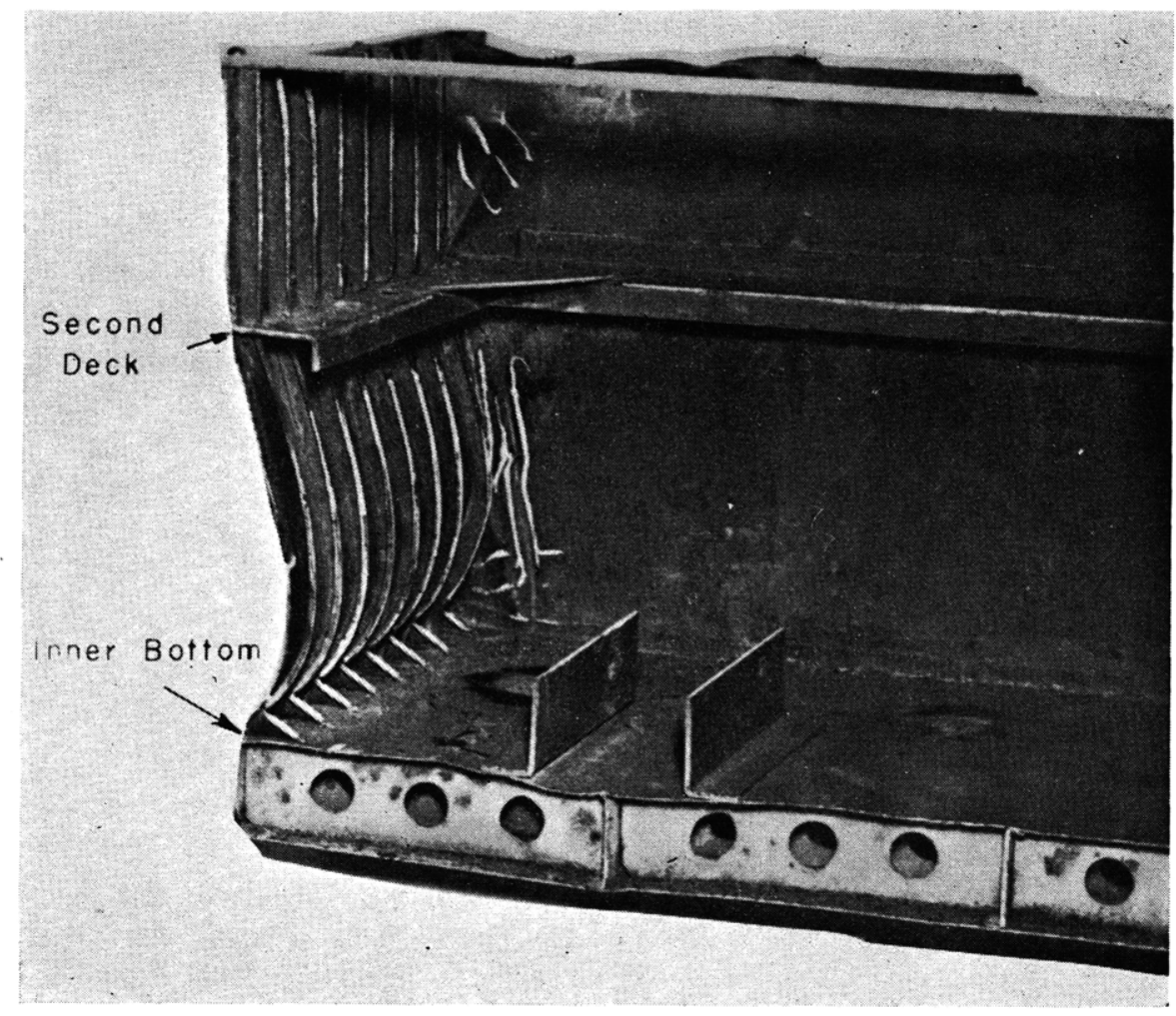

Fig. 14 Damage pattern to merchant ship hull $\left(1 / 35^{-}\right.$scale model, noncontact explosion)

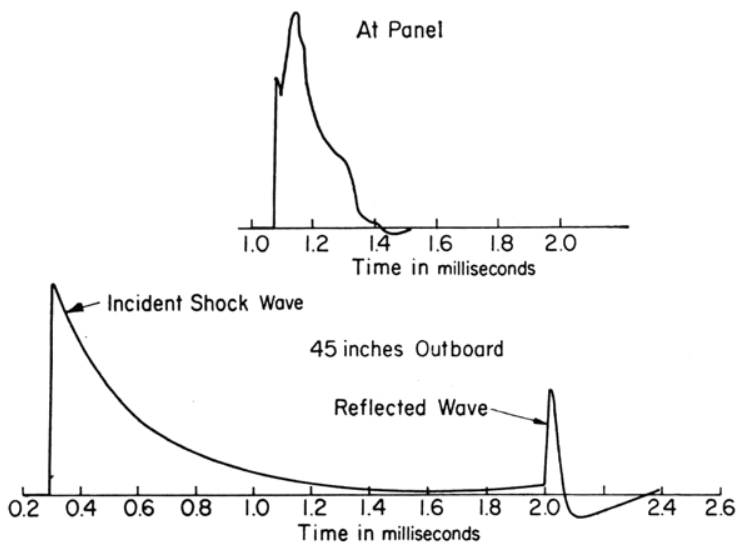

Fig. 15 Pressure near side shell

mechanism it is possible, under certain circumstances, that 60 per cent and more of the energy encountered in plastic deformation (damage) is coming from this early bubble expansion and only 40 per cent or less from the shock wave.

In spite of these complications it is possible to estimate maximum deflection of a single stiffened hull since in many cases of practical interest these

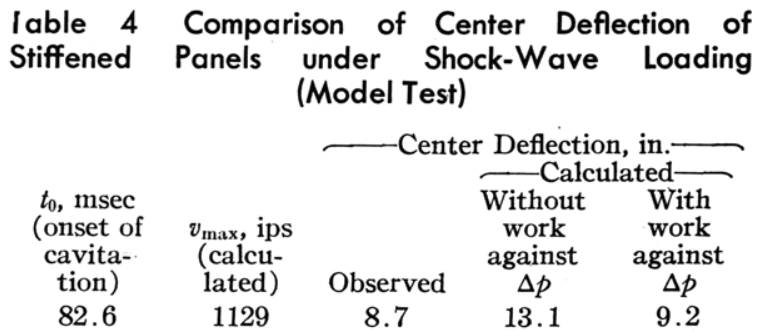

later contributions are small. Based on the calculations of an initial kickoff velocity (Appendix 2 ), the plastic deformation is calculated by considering membrane stresses in the shell plating and disregarding the stiffeners as strength members, since they tilt for small deformation. Instead, the stiffeners are considered to be spread uniformly over the shell plate. It is necessary to include in the energy balance not only the kinetic energy of this plating and the work of plastic deformation [16] but also the work against the air pressure as the plate deforms, since this deformation occurs with cavitation pressure at the outboard side of the shell. The adequacy of this approach is shown in Table 4 for a model test 


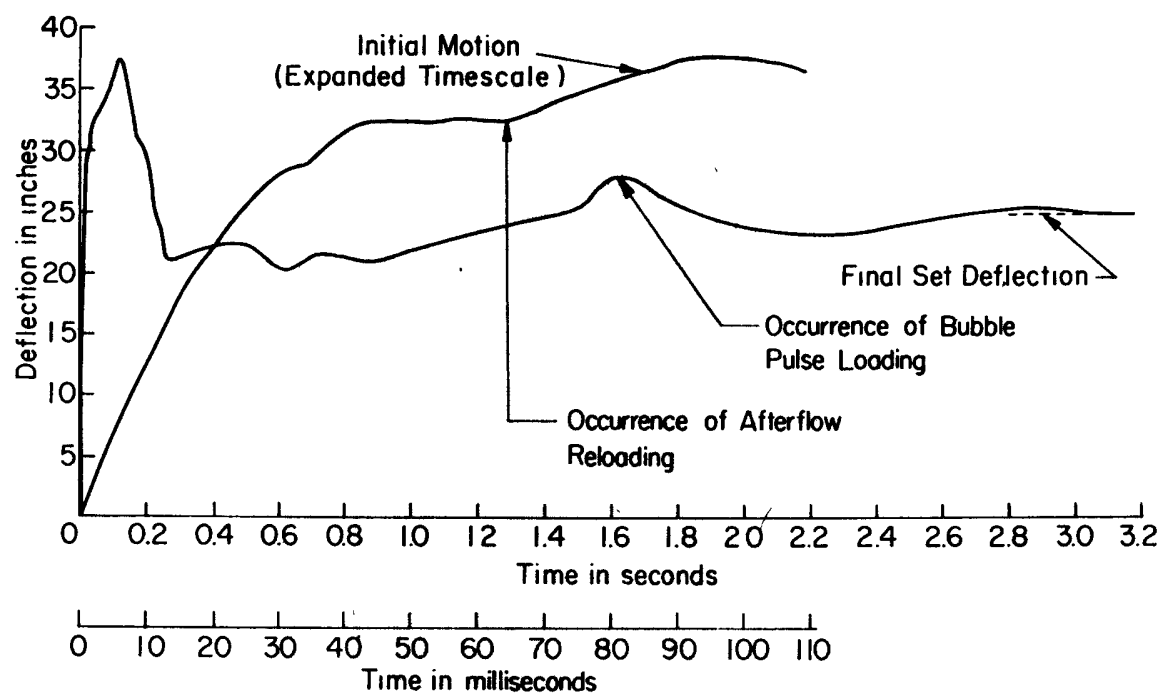

Fig. 16 Deflection history for side shell

with a $3 / 8$-scale model of a single plane stiffened ship shell. For further details of the simplified calculations, see reference [10]. For a brief review of the problems of dynamic plastic deformations of structural elements refer to [17].

Generalizations of such results require great care and careful appraisals of range of applicability of the formula and the validity of the underlying concept, since the theoretical treatment was carried out using great simplifications. In the explosive loading the water mass moving with the plate (Appendix 2), as well as the energy delivered by closure of the cavitation space, was neglected. The treatment of the stiffened shell neglected bending stiffness of the stiffeners, treated the shell plating as a membrane, and disregarded dynamic effects on the yield stress and the dishing of the plating between stiffeners.

Another type of deformation becomes very pronounced if the shell stiffening is relatively strong with respect to the plate stiffeners, as in the case for destroyers, Fig. 17. The load exerted by the shell and the heavy longitudinals in a destroyer may cause the bulkhead to buckle, Fig. 18 which in turn can lead to loss of watertight integrity between compartments.

It is frequently necessary to estimate how deflections change as function of attack severities. Instead of the more elaborate, though still simplified, calculations described previously, it is often adequate to apply the experience gained with clamped plates (Appendix 3) and use the rule that the deflection varies approximately with $1 / R$. Utilizing the concept of shock-wave energy density the effect of the charge size is included, and the plastic deflection is found to be proportional, at least approximately, to $W^{0.5} / R$ for high-explosive charges.

For a liquid-backed shell (tanks), the reaction of such ship plating can also be calculated by the concept developed in Appendix 2. Except for the initial high peak pressure, the plate is transparent to the shock wave. The inner bulkhead of the tank, therefore, sees a pressure loading very similar to the shell, Fig. 19. The fact that a tank is not completely filled does not relieve the inner bulkhead of this load, since the relief pressure from the tank surface can make itself felt only as the reflection of the transmitted wave at the surface of the liquid in the tank.

\section{Bottom Structure}

The hull damage resulting from an explosion under the ship's bottom is somewhat different. Not only is a stronger and more complicated structure subjected to the explosion forces but the ship is now in the way of the upward migration of the bubble.

The bottom of a ship is also a stiffened plate but the stiffeners, especially the longitudinals, are much heavier than the stiffeners of the side shell. The initial structural segment to be considered is the bottom plating between longitudinals and transverses. Typical dimensions for such a plate are $3 \mathrm{ft} \times 10 \mathrm{ft}$. For a shock wave with $\theta=1 \mathrm{msec}$, the dimensions are still not large with respect to the product of cavitation time $\left(t_{0}=0.3 \mathrm{msec}\right)$ times sound velocity, that is, the diffraction time (Appendix 2). For a void bottom, however, the initial bottom-plating kickoff (for adequate severity of attack), can lead more 
readily to dishing of the bottom plating because of the large mass of the longitudinals. The induced motion of the transverses and longitudinals will then initiate the motion of the innerbottom plating.

If the bottom is a double-bottom structure completely filled with liquid, the bottom shell plating can acquire a velocity which is about one half that of the air-backed bottom plating, and cavitation does not occur as the maximum velocity is developed; see theory for water-backed plate, Appendix 1. For identical attack conditions, dishing of the bottom plating is therefore much less than for the corresponding air-backed plate, and the velocity transmitted through the longitudinals fnd transverses is also less. The inner bottom, however, will be subjected to the wave transmitted into the tank Fig: 19, and will take off with nearly twice the velocity of the bottom plating. Dishing of the inner-bottom plating is, there-
fore, well possible.

A double bottom; partially filled with liquid, is the most common case. In this case the velocities for bottom plating, transverses, and longitudinals are reduced, and the high velocity of the inner bottom is not possible because of the air gap between the plate and the liquid surface. A spray, however, will develop as a result of the reflection at the free surface and will load the inner bottom, but this gradual loading will not produce the high accelerations occurring in the case of direct contact between liquid and inner bottom. The optimum amount of liquid loading in the bottom can be determined experimentally.

The over-all velocity of such a bottom as transmitted to foundations can be obtained with reasonable accuracy by disregarding the details of the loading and response process and treating, instead, the bottom as a uniformly distributed mass. This velocity can then be calculated based on the "plane unrestrained plate" theory, and the maximum velocity thus calculated agrees well with the observations.

The strength of the longitudinals and transverses in the bottom structure is such that a relatively large amount of the kinetic energy is absorbed in bending these beams. For the same attack severity the final deflection is therefore much less than for the side shell, though not necessarily less serious in terms of consequences.

The motion of the bottom transmits forces to the side shell and to the bulkheads which transmit them to the deck thus causing an upward motion of the ship section. This process is demonstrated by the history of the initial absolute displacement of two locations of a Liberty ship, which was subjected to a rather severe noncontact explosion,
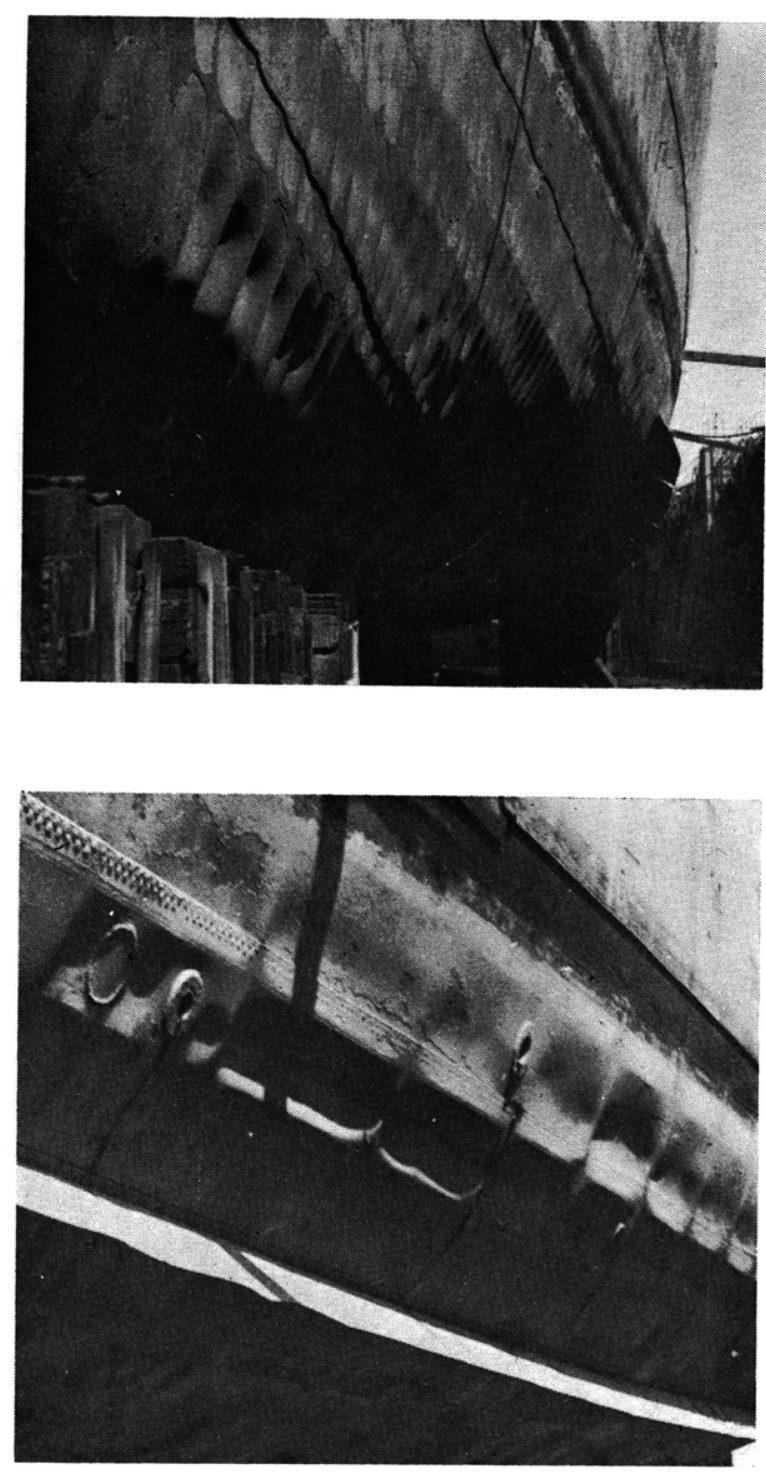

Fig. 17 Shell dishing of destroyer

Fig. 20. These histories indicate that the bottom deforms permanently between bulkheads, as shown by the offset of the displacement histories. In addition, the bottom vibrates as a cross-stiffened panel. Superimposed on these vibrations is an over-all displacement of this section of the ship.

A rigorous elastic treatment for this case was attempted by Wah and DeHart [18]. They assumed an initial kickoff velocity for the plane bottom and then considered the later motion of the ship's bottom and decks by means of a superposition of normal modes of vibration of the orthotropic plates formed by these structures and limited by bulkheads and ship sides. 


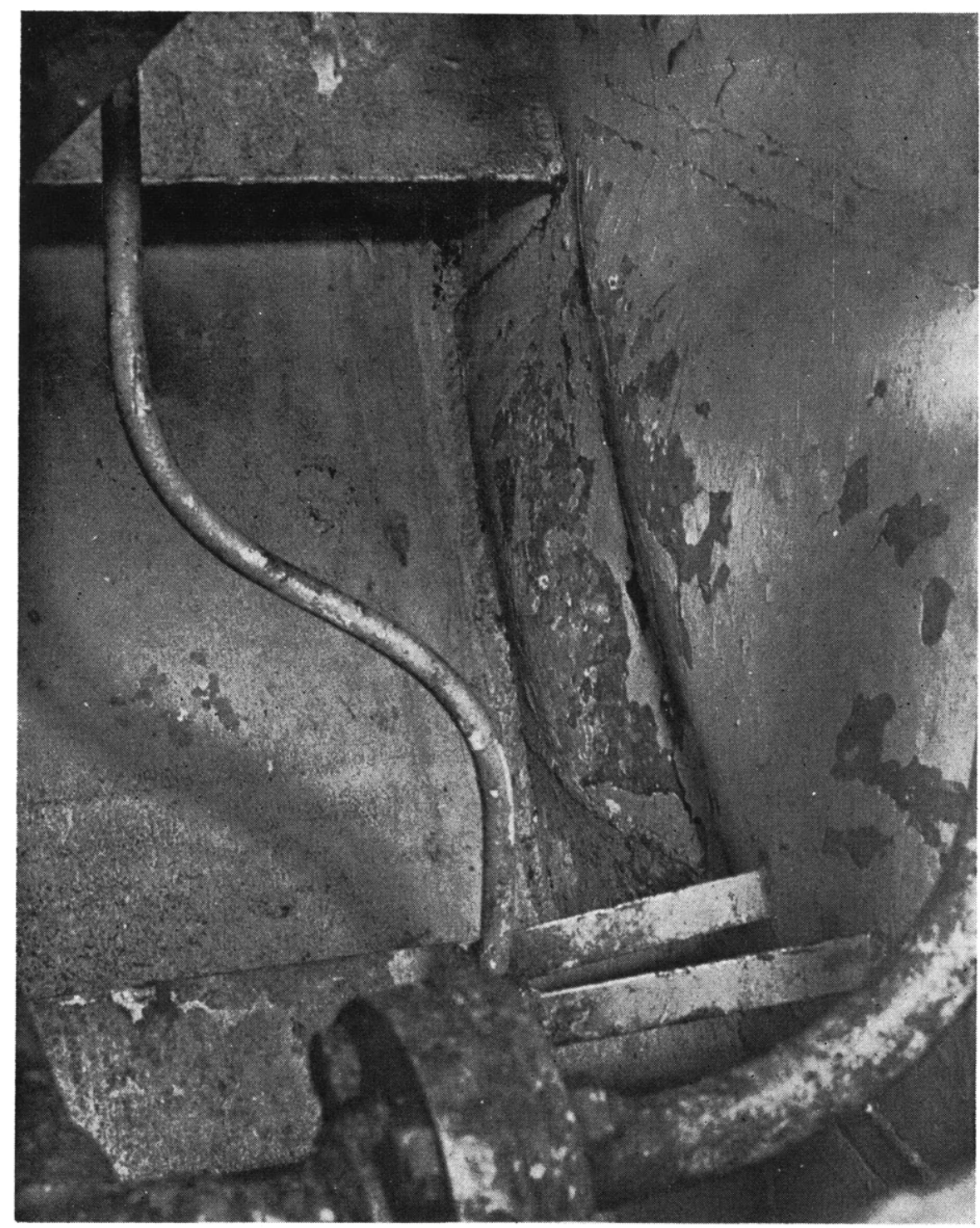

Fig. 18 Bulkhead buckling due to inboard deflection of longitudinals

Frequently the bottom damage is the result of the shock-wave loading alone, but more frequently the later bubble pulses contribute and increase the shock-wave deformation. Since the bubble-pulse loading occurs later than the shock wave because of the time required for a bubble pulsation, the bubble-pulse loading may be directed against a different portion of the bottom structure than the shock wave. The offset between the two locations depends on ship speed and pulsation time of the gas bubble.

Often the ship is in the way of the migrating gas bubble, and when in this position, one of the bubble pulses may occur near the ship's bottom.

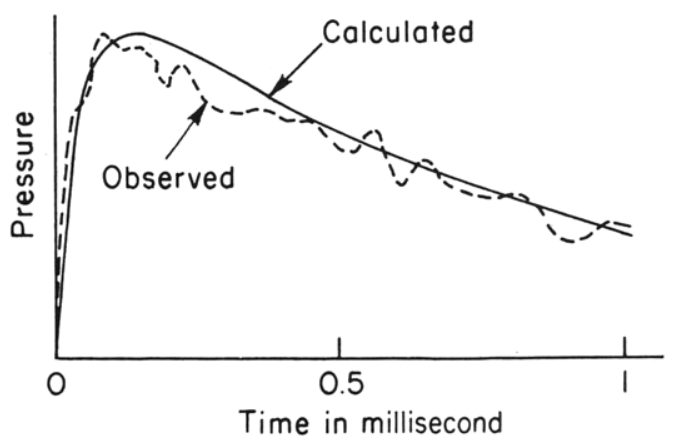

Fig. 19 Pressure transmitted through waterbacked shell 


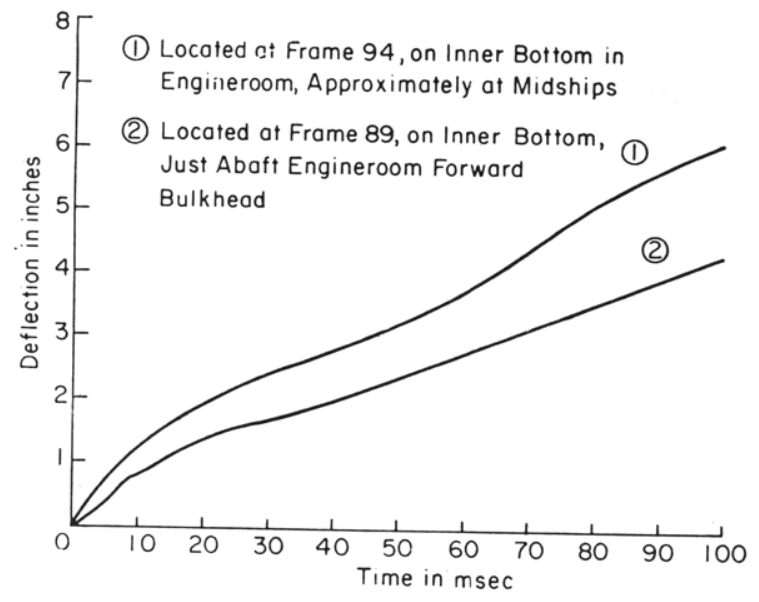

Fig. 20 Absolute displacement at two locations of a Liberty ship (attack resulted in no serious hull damage)

Then a very high and very localized loading develops which causes the bottom structure to give way under the excessive load. If the bottom is sufficiently strong and if the bubble-pulse loading is not too severe, the bottom will be deformed or brought to rupture at the "restraints" offered by the bulkheads, Fig. 21. If the first bubble pulse occurs close to the bottom, the intense localized loading causes a hole in the bottom structure, Fig. 22, with the release of the remaining bubble energy into the attacked compartment.

Any deformation of the bottom is naturally connected with a severe load transmission into the bulkheads. This can lead to buckling of the bulkhead plating, Fig. 23, and deformation of bulkhead stiffeners which in turn may cause tearing and loss of watertight integrity.

\section{Response of Ship Girder}

It is apparent that different sections of the ship will encounter different peak velocities of the bottom structure and different average velocities for the cross section, depending on the distance from the explosion and the angle of attack. Any such variable velocity distribution along the ship will naturally result in bending of the ship's girder, superimposed on the rigid-body motions of heaving and pitching. This bending naturally will be affected further by the time-dependent pressure distribution along the bottom generated by the expanding and contracting gas bubble. The theory of the response of the ship's girder to this pressure field [19] is briefly described in Appendix 4.

Not much light was shed on this response phase until ground mines equipped with proximity fuses came into use in World War II. Typical results of excessive hull girder stresses caused by such explcsions were the "broken backs" of ships. An example of this type of failure is shown in Fig. 24.

Intensive studies of this response phase using ship hulls were conducted during and since World War II to explore the development of the "whipping damage" and its relation to the phases of the underwater explosion. By measuring the absolute displacement of the ship at several frames at regular time intervals after the explosion, centerline displacement curves can be determined. Two

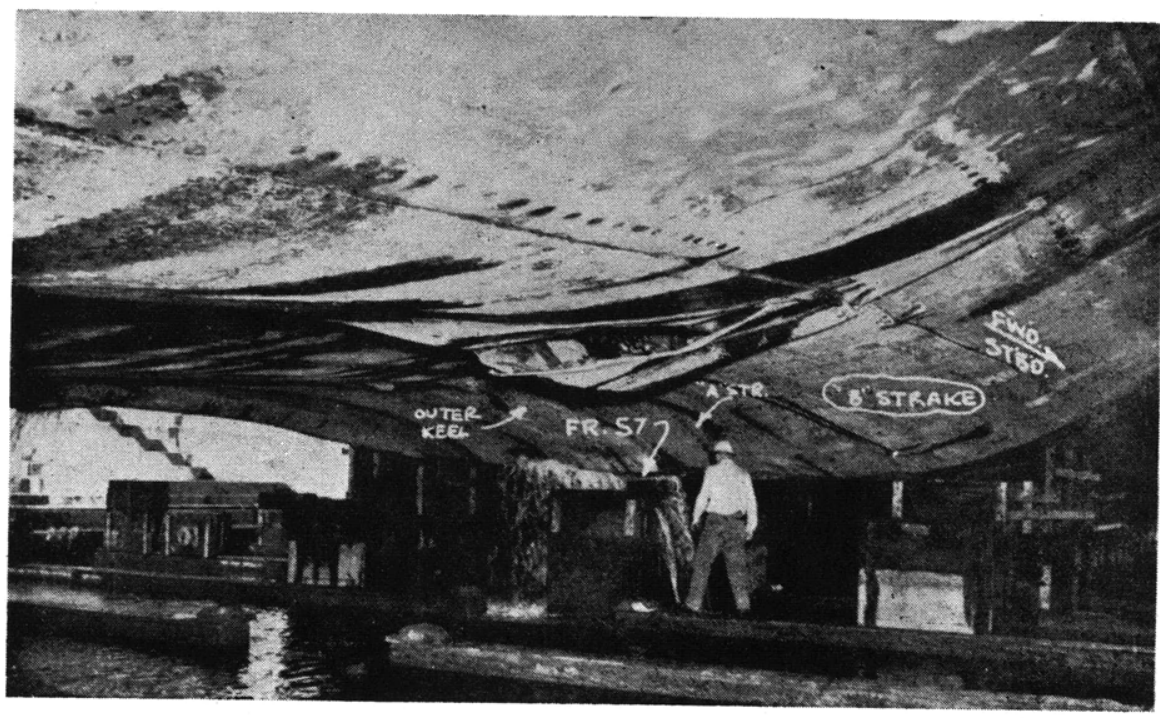

Fig. 21 Bottom deformation of a cruiser due to bubble pulse loading 


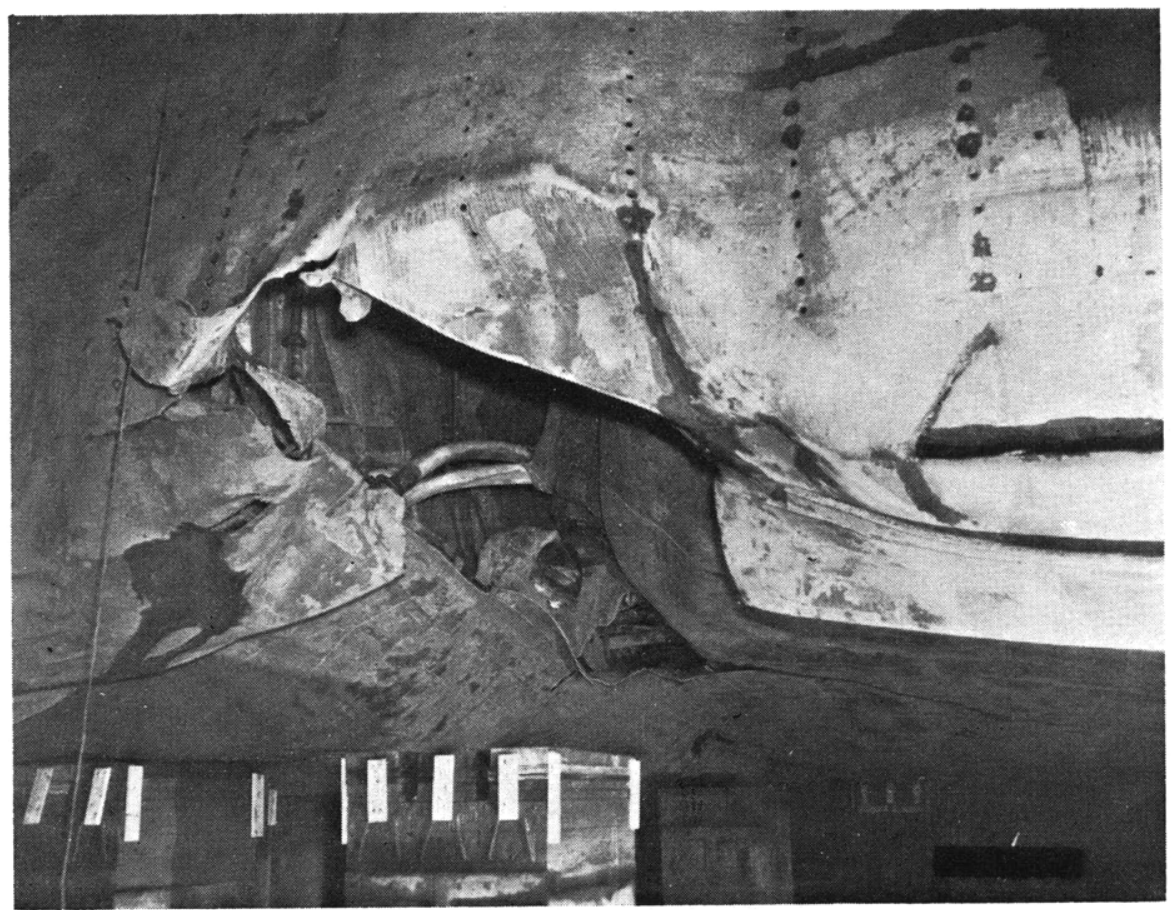

Fig. 22 Hole in Liberty ship bottom from bubble pulse loading

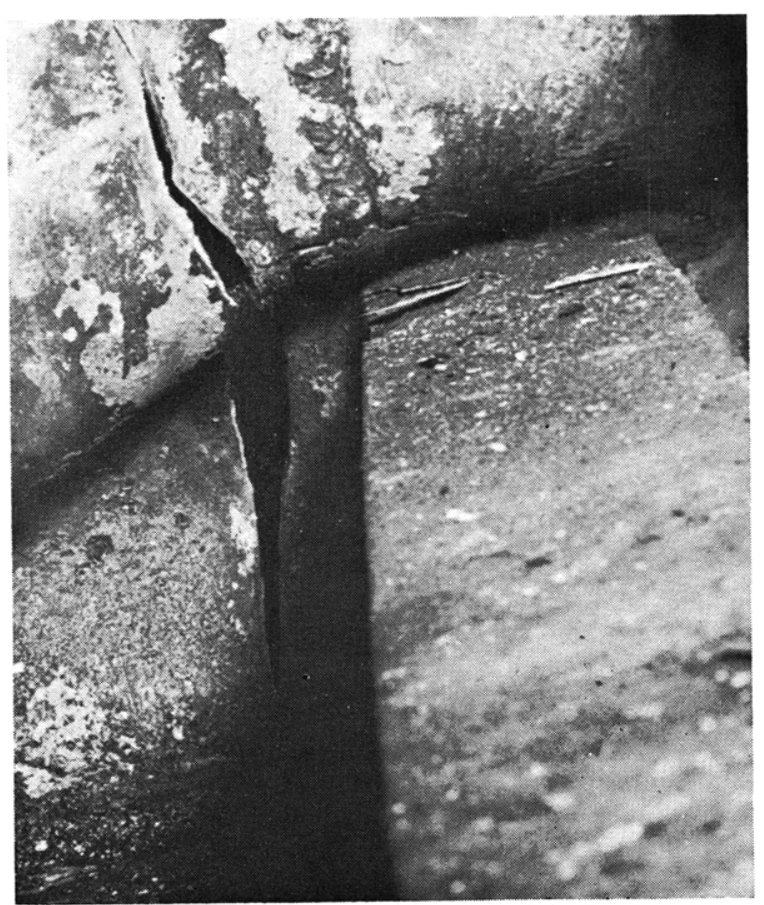

Fig. 23 Bulkhead buckling and rupture resulting from inboard motion of bottom longitudinal

typical examples obtained for an actual cruiser test are shown in Fig. 25. The bending of the ship's girder is superimposed on the rigid-body motion (heaving and pitching).

An example of the bending response of a ship attacked near midships under bottom by a noncontact explosion is shown in Fig. 26, which presents the hogging and sagging of the ship following the explosion. The midship deflection versus the straight connection bow/stern is plotted and the occurrences of the bubble pulses are indicated. It becomes apparent that the bending is aifected considerably by these bubble pulses for two reasons:

1 The bubble migrates upward bringing later pulsations closer to the ship.

2 The respective loading cycles may be in phase with the girder vibration.

The girder strength may be exceeded during this whipping response. It usually happens that failure starts when the ship's bottom, the lower flange of the hull girder, is compressed beyond its buckling strength. This can occur as a result of the initial loading or as result of later bubble loading after one or two oscillations of the gas bubble. During the later reversal of the load during the hipping process the buckled area is pulled excessively and may tear. At the same time the deck in this area may buckle. In addition, a severe vertical wrinkle in the shell develops, as shown in Fig. 27. Later loading phases 


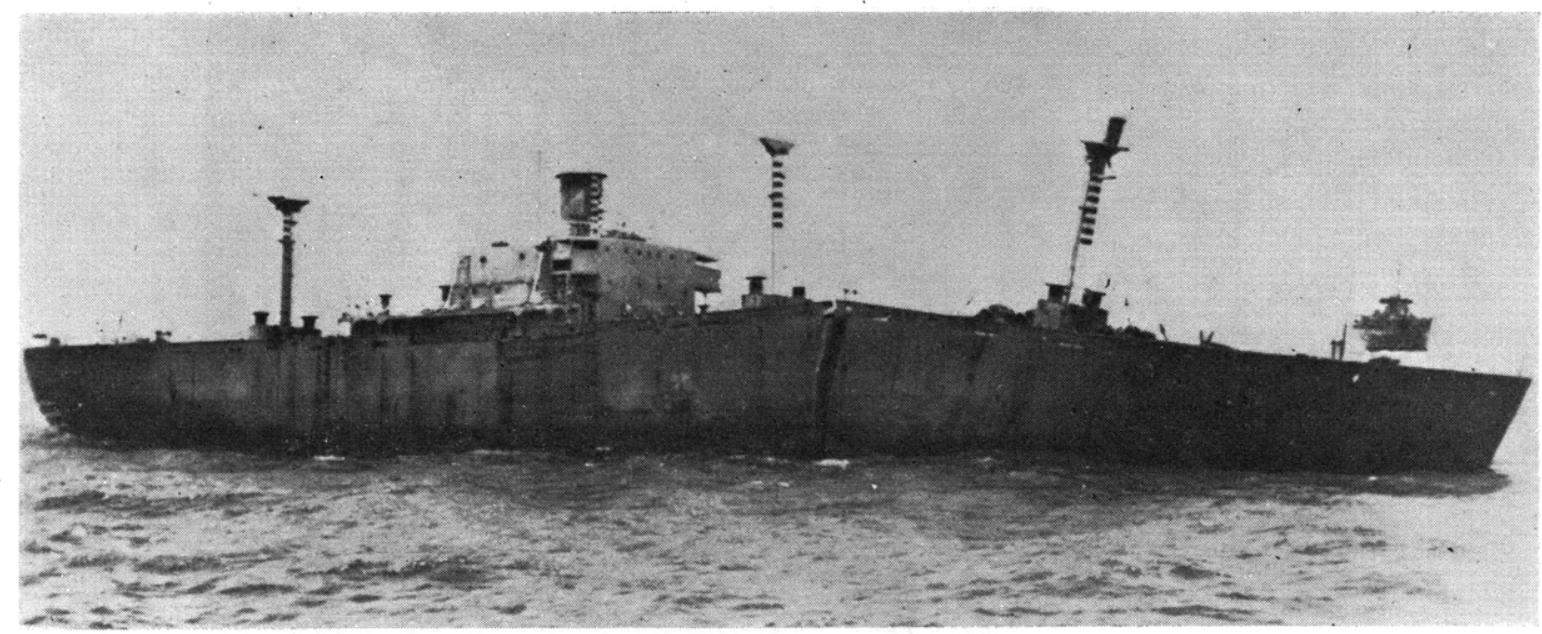

Fig. 24 Failure of hull girder (Liberty ship, noncontact explosion)

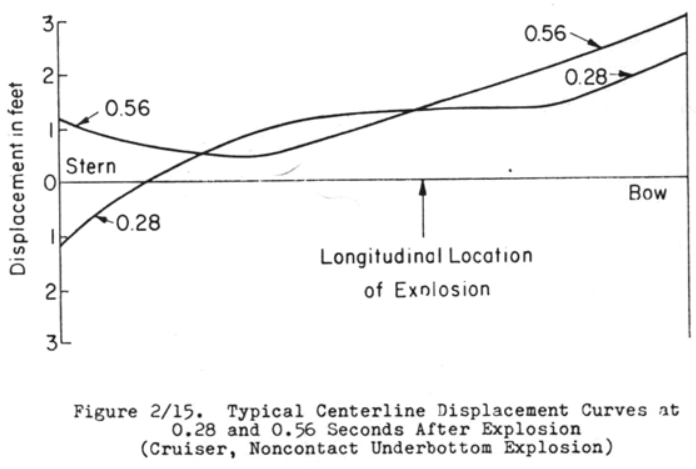

Fig. 25. Typical centerline displacement curves at $\mathbf{0 . 2 8}$ and $0.56 \mathrm{sec}$ after explosion (cruiser, noncontact underbottom explosion)

may lead to another load cycle exaggerating the original damage.

After such an attack one or several such buckled regions may have developed in the ship. An example is shown in Fig. 28 for the case of two such hinges in the ship's girder. For severe attacks one hinge usually develops in the attack area. Others may occur depending on the severity of the girder vibrations which the explosive loading excited. Weaknesses and discontinuities in the shìp's girder will aggravate the development of such a hinge.

\section{Principal Types of Equipment and Machinery Damage and Response}

During the various phases of hull response the ship is subjected to high transient velocities followed by lower velocities of the heaving, pitching, and whipping response which can be associated with relatively large displacements. These shock motions can cause shock damage; that is, failure

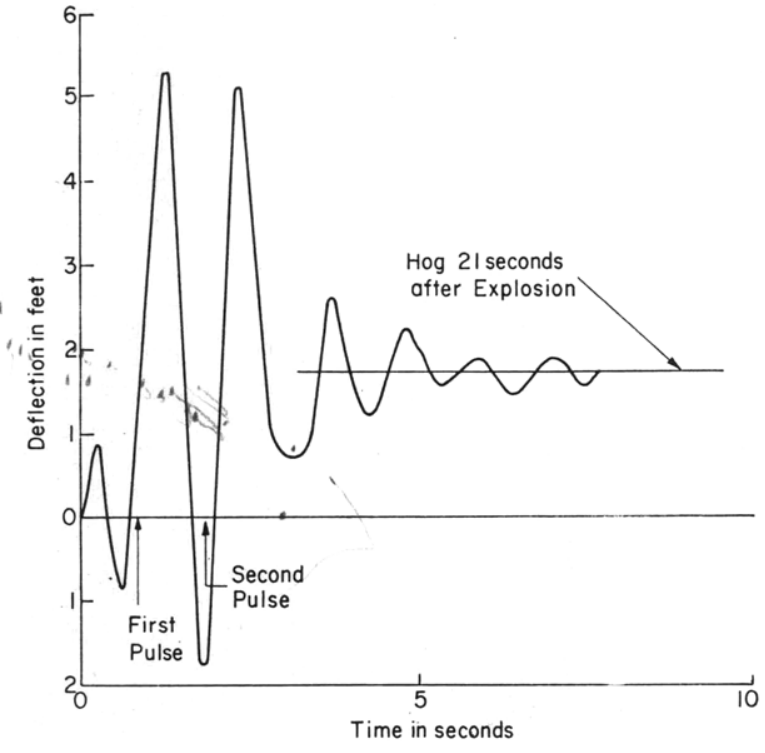

Fig. 26 Hogging and sagging of cruiser hull

of equipment, machinery installations, and foundations.

Typical failure due to plastic deformation of foundation is shown in Figs. 29 and 30. Typical brittle failures are demonstrated in Figures 31 through 33 for the foundations or supports made of cast iron or cast aluminum. Typical shock damage to hold-down bolts is shown in Fig. 34, indicating various degrees of shearing and stretching of the bolts. Another shock-damage pattern comprises failures of connections between different installations or pieces of machinery which are the result of relative motions between the two. 


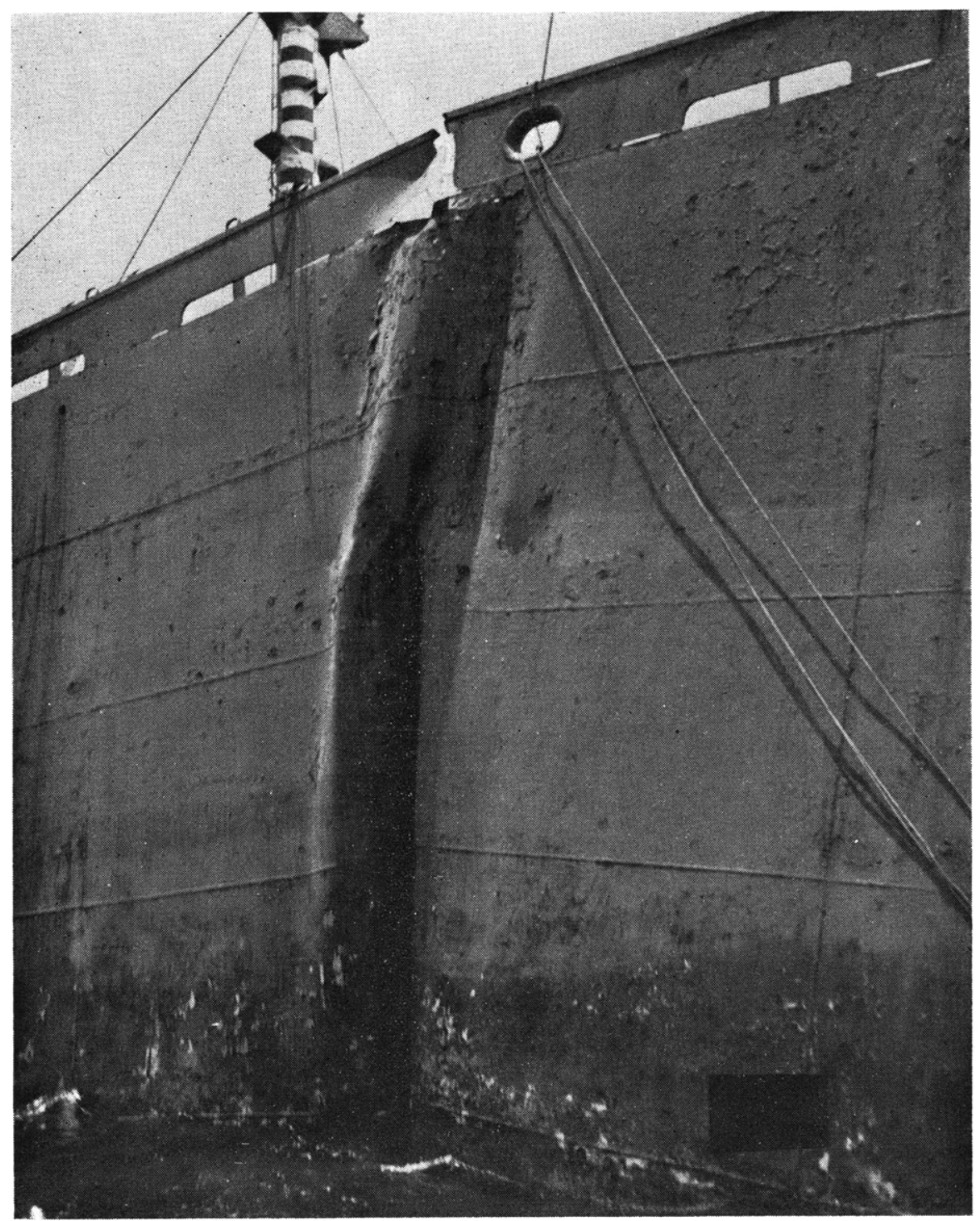

Fig. 27 Wrinkle in starboard side at Hold 2

Typical examples are failures in steam pipes, Fig. 35.

Ejection of insufficiently secured equipment or components, such as radio tubes and capacitors, Fig. 36, or of whole subassemblies, Fig. 37, and loosening of brickwork in boilers, Fig. 38, are typical examples of another group.

These illustrations of typical shock failures must be supplemented with the case of shock damage due to resonance for installation on soft mounts in areas where typical ship frequencies are excited, such as in decks and superstructures. Finally shock damage can occur by impact of two installations which would have elastic response if sufficient clearance between the two had been macie available.

Shock damage is the result of the shipboard shock environment which is usually described in terms of velocity histories for the respective locations and installations. An example of a typical velocity history is shown in Fig. 39. Shock environment may also be expressed through the response of linear single-degree-of-freedom systems to the shock motion for a wide range of frequencies of these oscillators [20]. An elastic undamped linear system $(n, \mathrm{cps})$ will respond to a given shock motion by a forced vibration. At some instant during this vibration a maximum deflection 


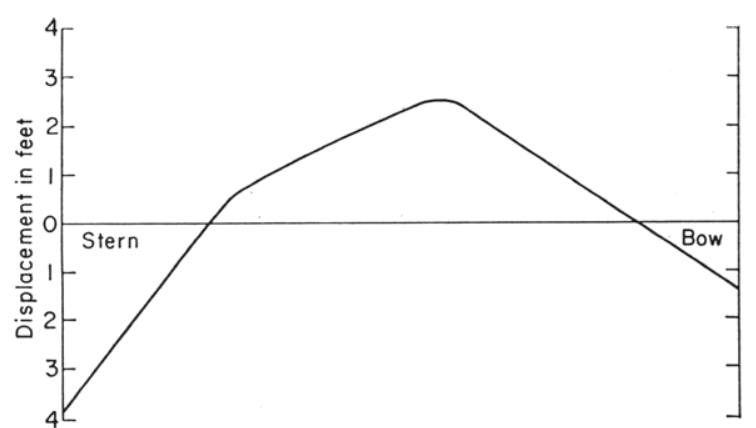

Fig. 28 Occurrence of two hinges in ship girder as a result of underbottom attack

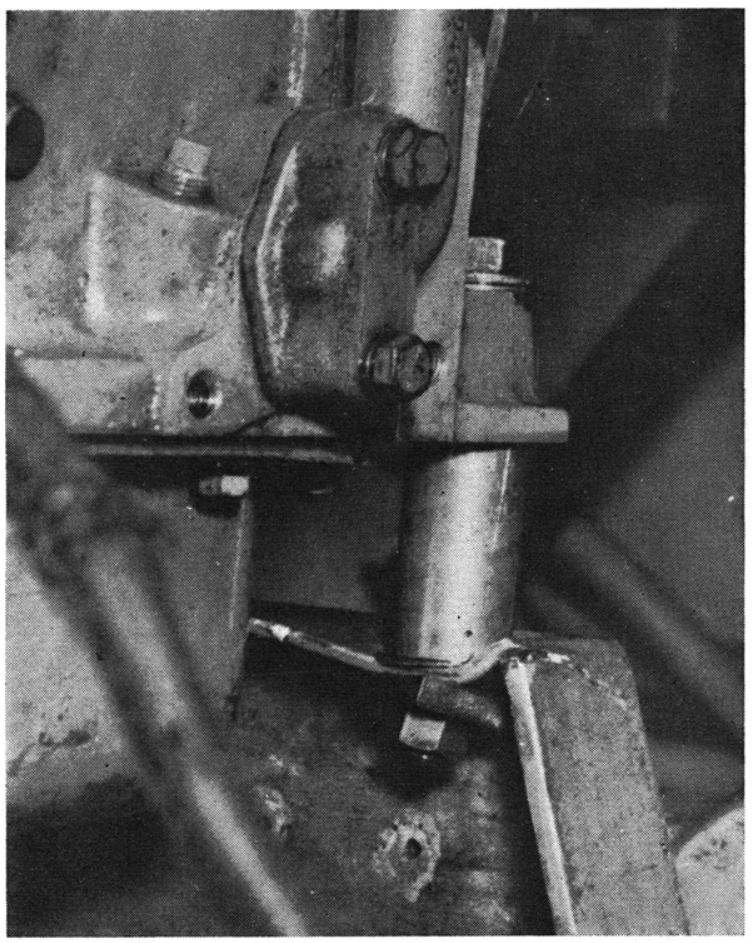

Fig. 29 Distortion of machinery foundation

amplitude $d$ of the oscillator will occur. These maximum values can be determined for any frequency in the range of interest and can be plotted as functions of this frequency. These plots are called the displacement shock spectra. The velocity shock spectrum and the acceleration shock spectrum are defined as the plots of the products of these displacements with $2 \pi n$ and $(2 \pi n)^{2}$, respectively; Appendix 5.

The relation of a velocity history to various shock spectra is shown in Fig. 40 for the case of a typical ship board shock velocity taken on a Liberty ship under mine attack (the attack caused only insignificant hull deformation.) This spe-

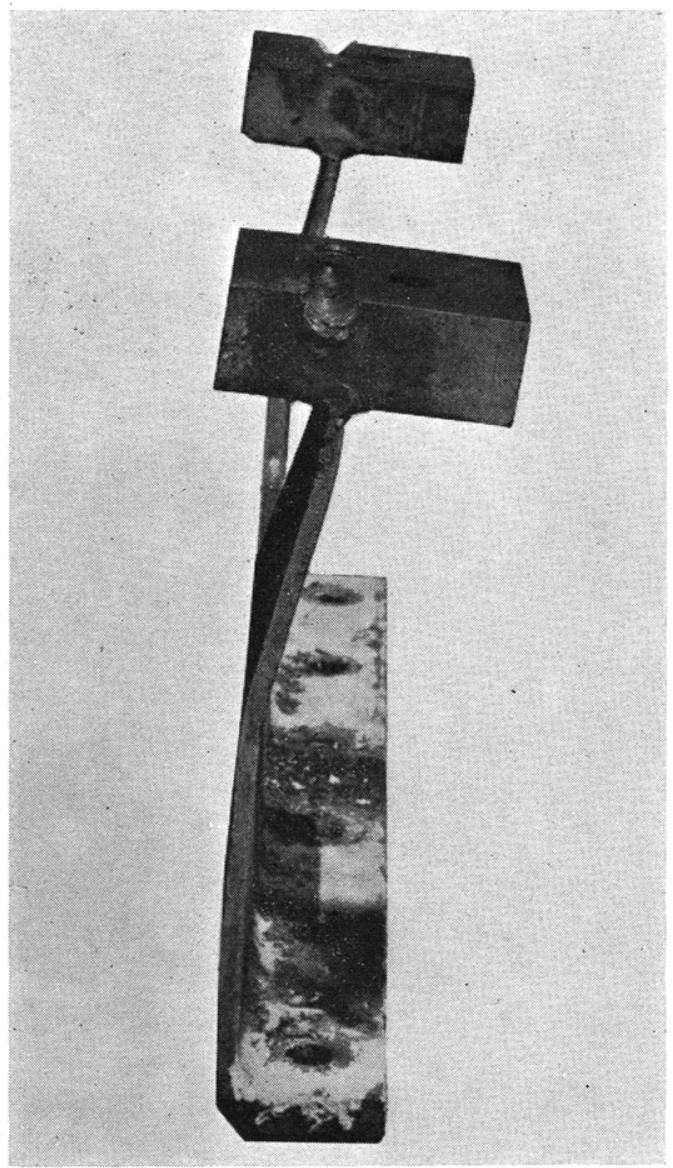

Fig. 30 Buckled destroyer turbine flexure plate

cific velocity history was chosen because it demonstrates that a considerable displacement is associated with a severe shock motion.

From the foregoing discussion on the hull response it is apparent that the shock motions differ throughout the ship [9]. Those sections of the hull that are directly subjected to the shock wave show the fastest rise to the peak shock velocity, bulkheads have somewhat slower rise times, and decks and superstructures have even slower velocity rises. A typical example of the shock velocity for three locations is indicated in Fig. 41 for a moderate shock severity. Again the three velocities were transformed into the shock spectra shown in the same figure.

The shock velocity varies not only throughout the ship, but also for a fixed location and for identical attack conditions with the stiffness and mass of the equipment installed there. In general, the larger the mass, the larger the rise time and the lower the peak velocity.

For hull-mounted equipment, this is immediately apparent from the calculations of the 


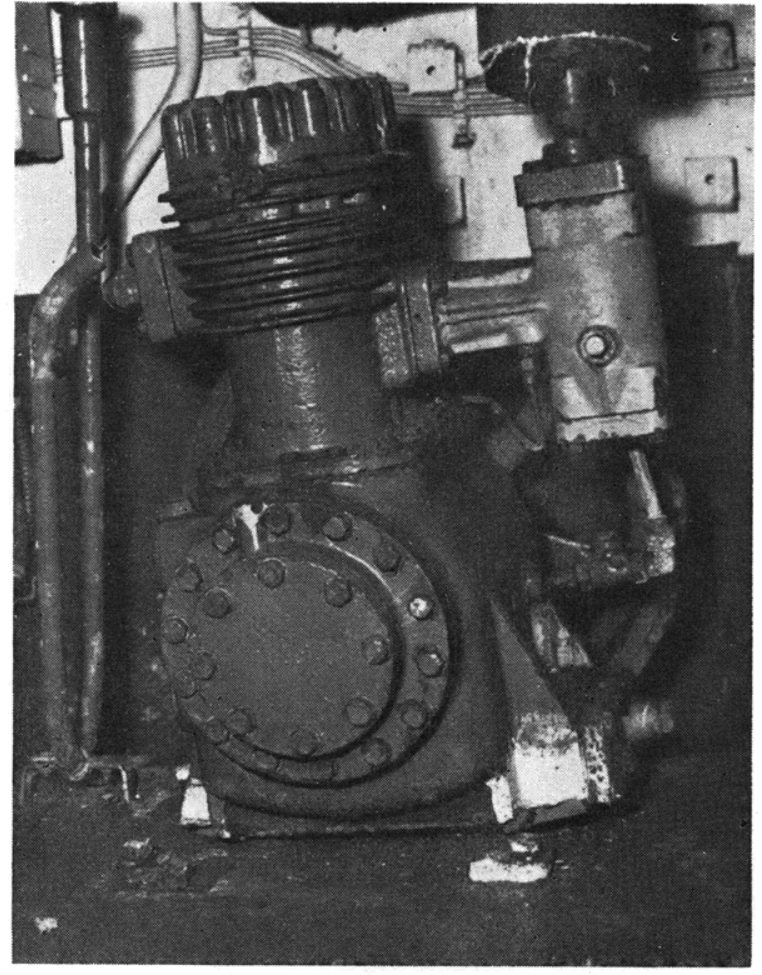

Fig. 31 Failure of air compressor foundation

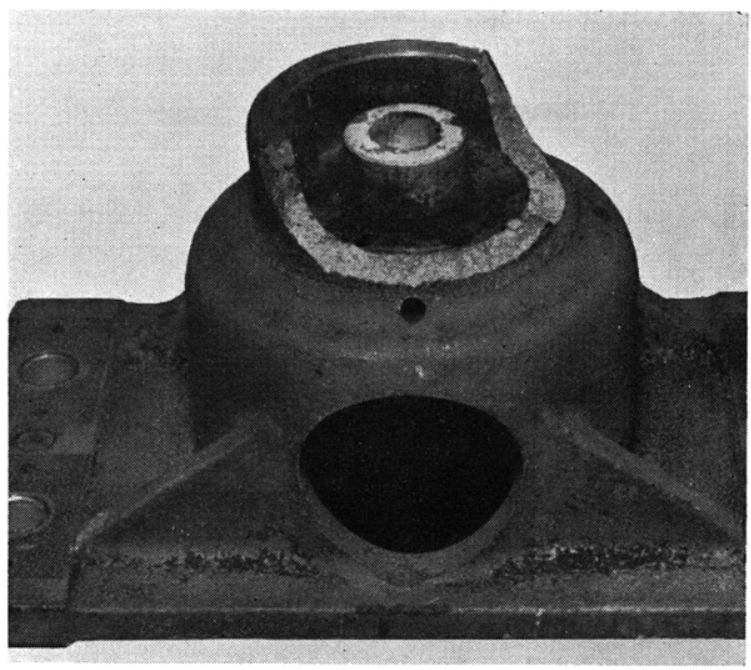

Fig. 32 Cracking of cast aluminum pedestal for radar antenna

kickoff velocity for this portion of the bottom structure. The mass per unit area of a liquidloaded double bottom of a ship is $M \sim 150$ to 200 psf. Installation of a light piece of equipment will not change $M$ significantly, but heavy installations such as the reduction gear will increase $M$ noticeably. Since the kickoff velocity depends on

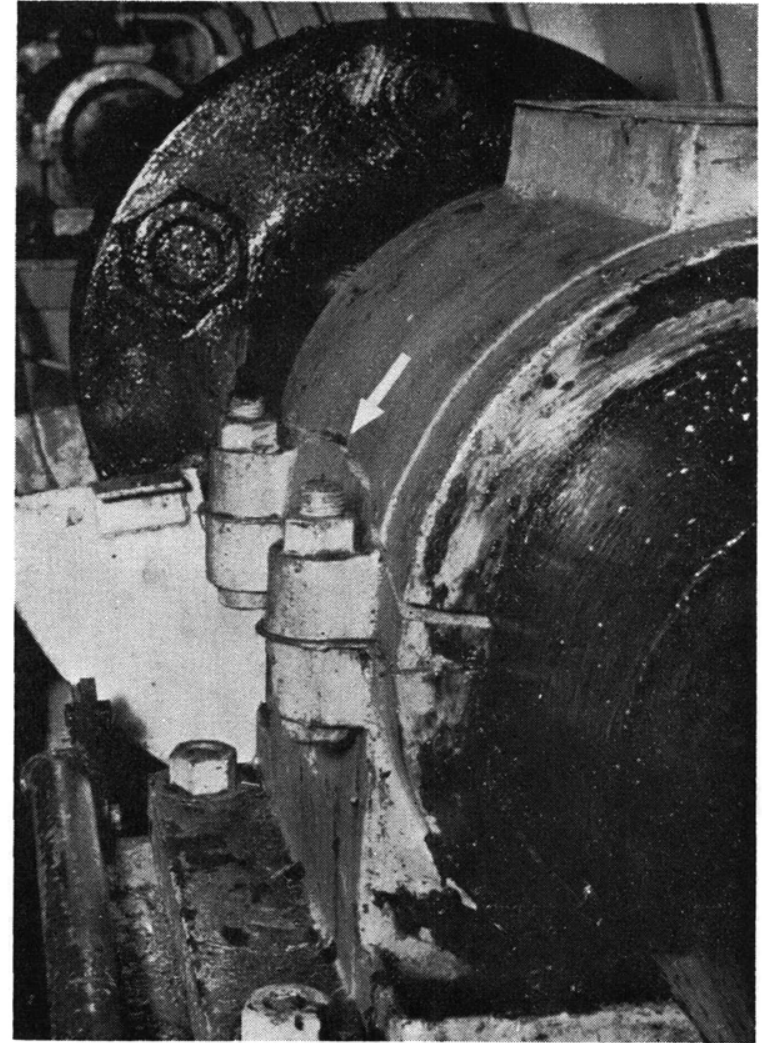

Fig. 33 Cracked top cap of main spring bearing

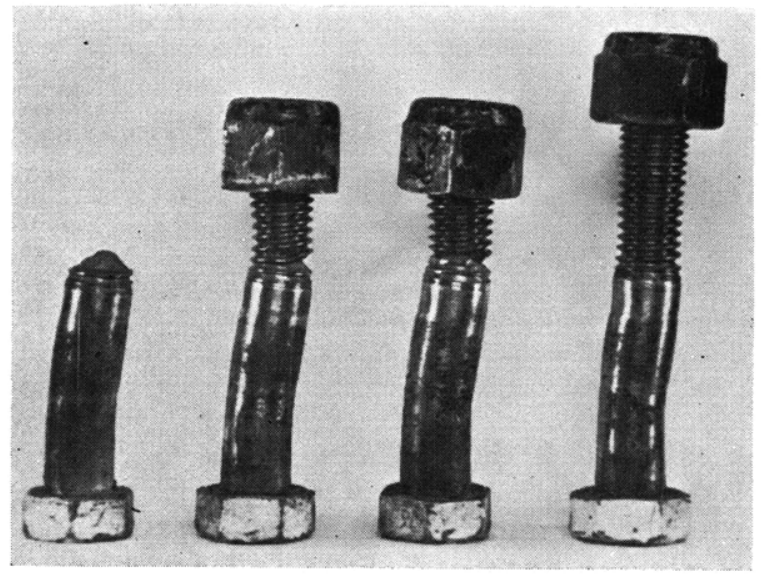

Fig. 34 Shear and tensile failure of main turbine holddown bolts

the parameter $z$ (Appendix 2) and since $z$ is proportional to $M$, it is apparent that the peak shock velocity for hull-mounted equipment and machinery varies very little for light installations, but decreases more and more for heavier installations.

The vertical shock velocity for a surface ship 


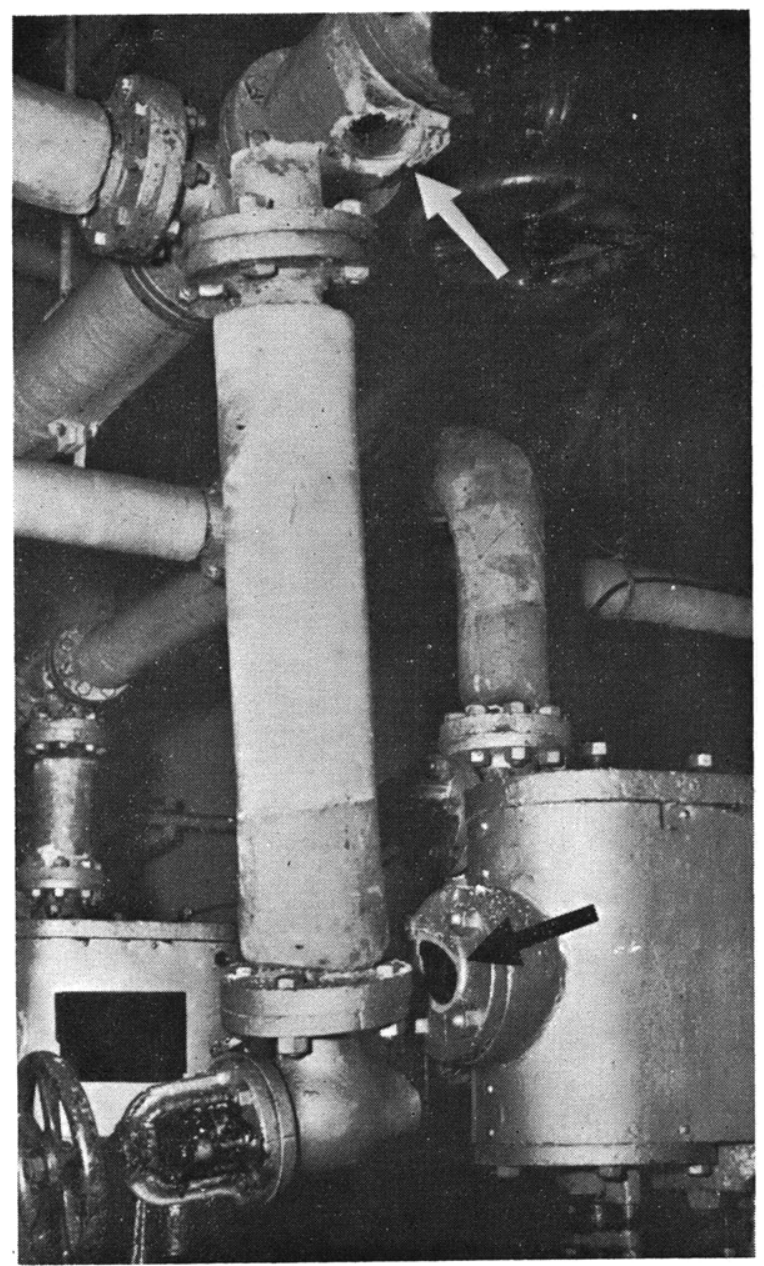

Fig. 35 Failure of exhaust steam piping and associated valve to ship's service generator

is predominant. This is due to the presence of the water surface. The horizontal shock velocity for bottom- and bulkhead-installed equipment or machinery can be as high as the vertical velocity (occasionally higher), but it is of short duration, indicating that only relatively small displacements occur in the athwartship direction. The vertical shock is coupled with significantly larger displacements.

Analytical problems concerning the interaction between a structure and dynamic loads exerted by an underwater șhock wave are summarized in $[21]$.

\section{Variation of Shock Environment With Attack Severity}

Since a ship can be subjected to a large variety of underwater explosions (variation in charge weight, standoff, relative attack geometry), the

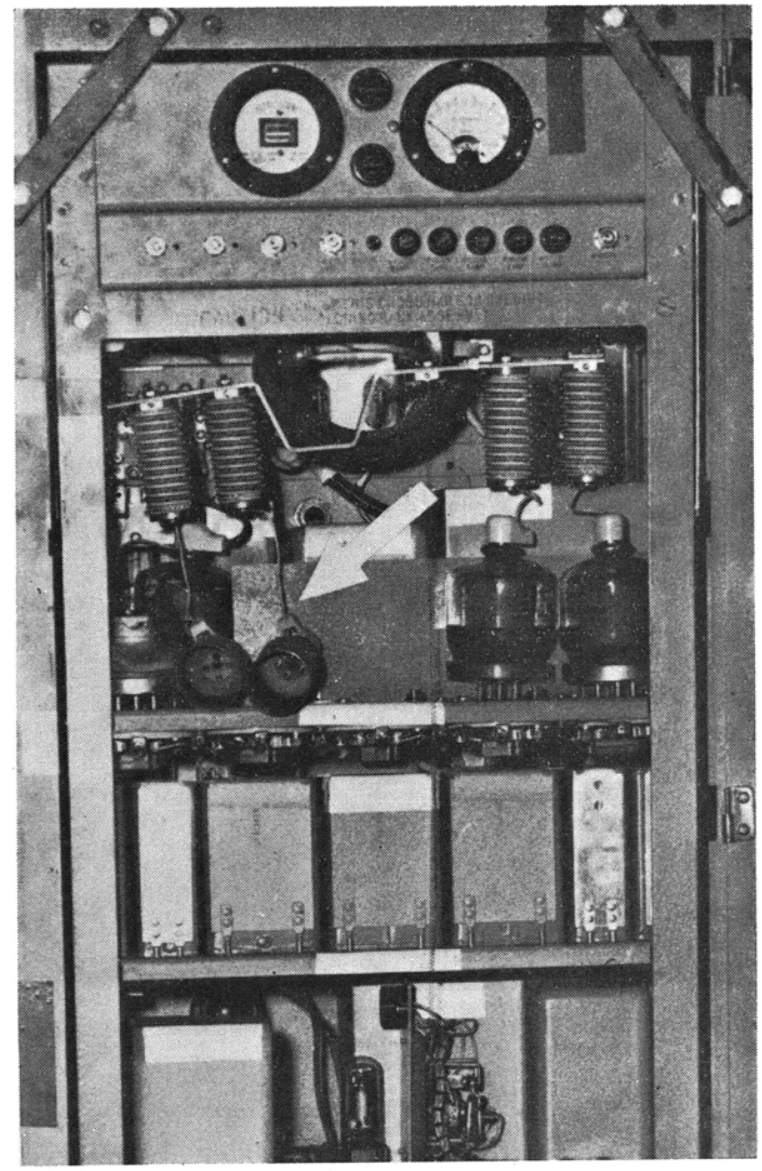

Fig. 36 Ejection of electronic components from cabinet

relation between shock velocity and attack severity and geometry must be determined.

The attack severity for high explosive charges such as mines is usually described by the energy density of the shock wave arriving at the ship's hull [9] and can, therefore, be measured as

$$
\frac{W^{1 / 2}}{R} \quad(=\text { maximum shock factor })
$$

Naturally the velocity of the hull must depend on the angle of incidence of the shock wave (Appendix 2). Just considering the energy density in this case,

$$
\frac{W^{1 / 2}}{R} \cos \alpha
$$

is found as the functional relation. However, even for glancing incidence $\left(\alpha=90^{\circ}\right)$ there is a loading on the hull so that more generally another "angle function" must be found, and usually a relation of this type

$$
\frac{W^{1 / 2}}{R}[\eta+(1-\eta) \cos \alpha]=\frac{W^{1 / 2}}{R} f(\alpha)
$$




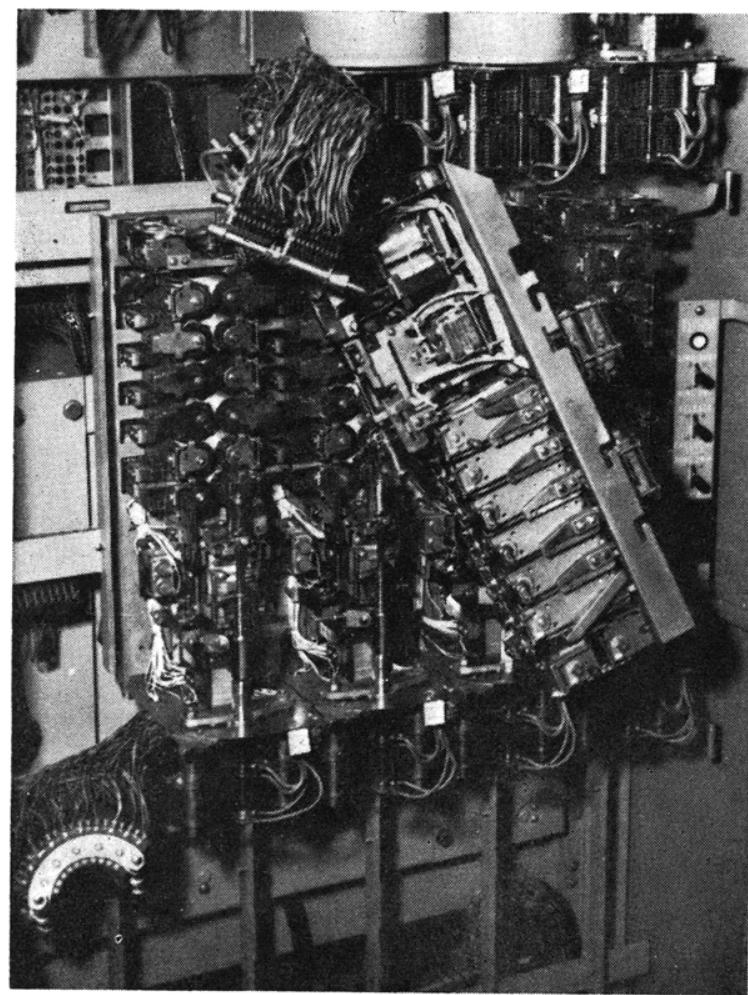

Fig. 37 Ejection of telephone switchboard subassembly from cabinet

is used, with $\eta$ determined from experiments.

In general, then, the shock velocities aboard a ship can be described for various attacks by

$$
V=\underbrace{C \frac{W^{1 / 2}}{R} f(\alpha) \cdot \bar{V}(t)}_{\text {shock factor }}
$$

where $C=C$ (ship type, location aboard ship, type of installation).

$\bar{V}(t)=$ "shock signature," showing typical variation of velocity with time.

The shipboard shock environment is thus treated by a series of normalized velocity histories $\bar{V}(t)$, one for each typical case. This description applies just as well for the horizontal shock velocities, with a different set of $\bar{V}(t)$, naturally, and the angle of incidence correspondingly modified.

However, the normalization is justifiable only for the response of elastic systems, that is, for the case of no hull damage. Moreover, it is restricted to light to moderate shocks, since for severe shocks the target motion resulting from the gas-bubble pulsation becomes noticeable. More precisely, the shock-wave-caused velocity is roughly proportionate to $1 / R$, whereas the bubble-caused dis-

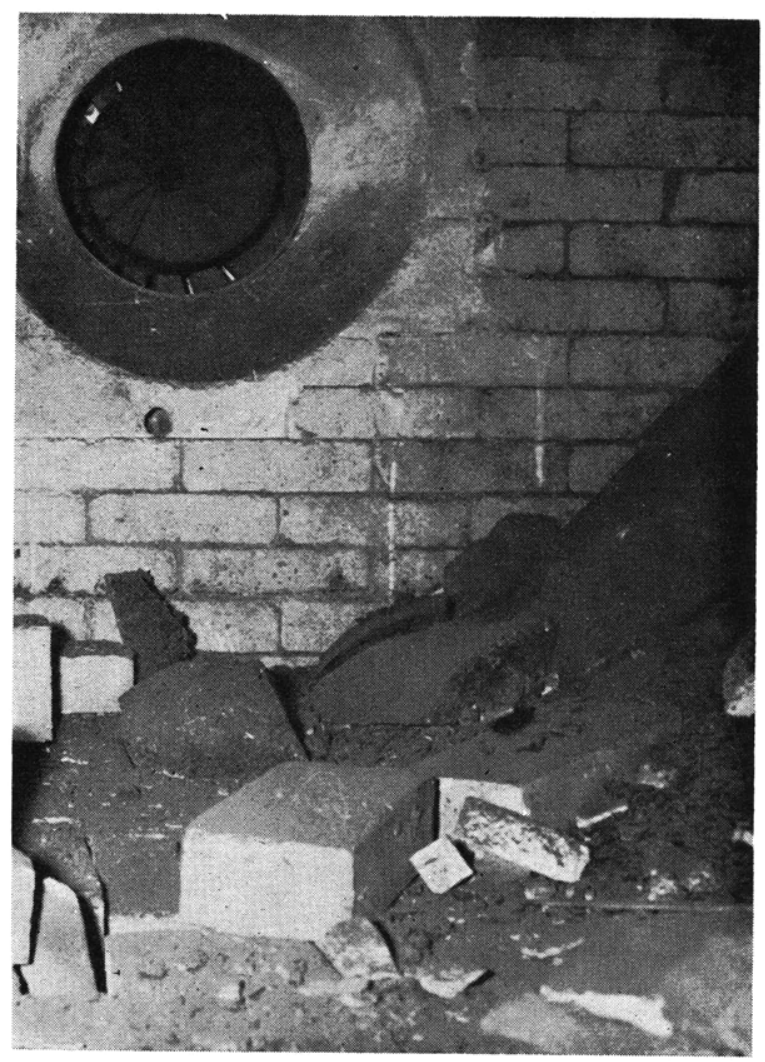

Fig. 38 Dislodged boiler brickwork

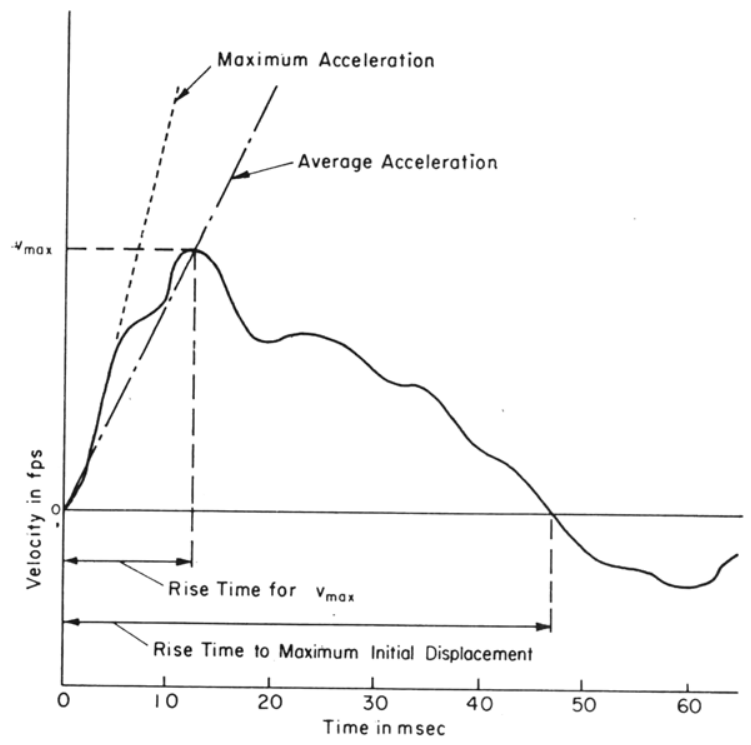

Fig. 39 Example of shock motion and terminology (mild shock)

placement changes more rapidly than $1 / R$ (Appendix 4). This effect makes itself apparent 

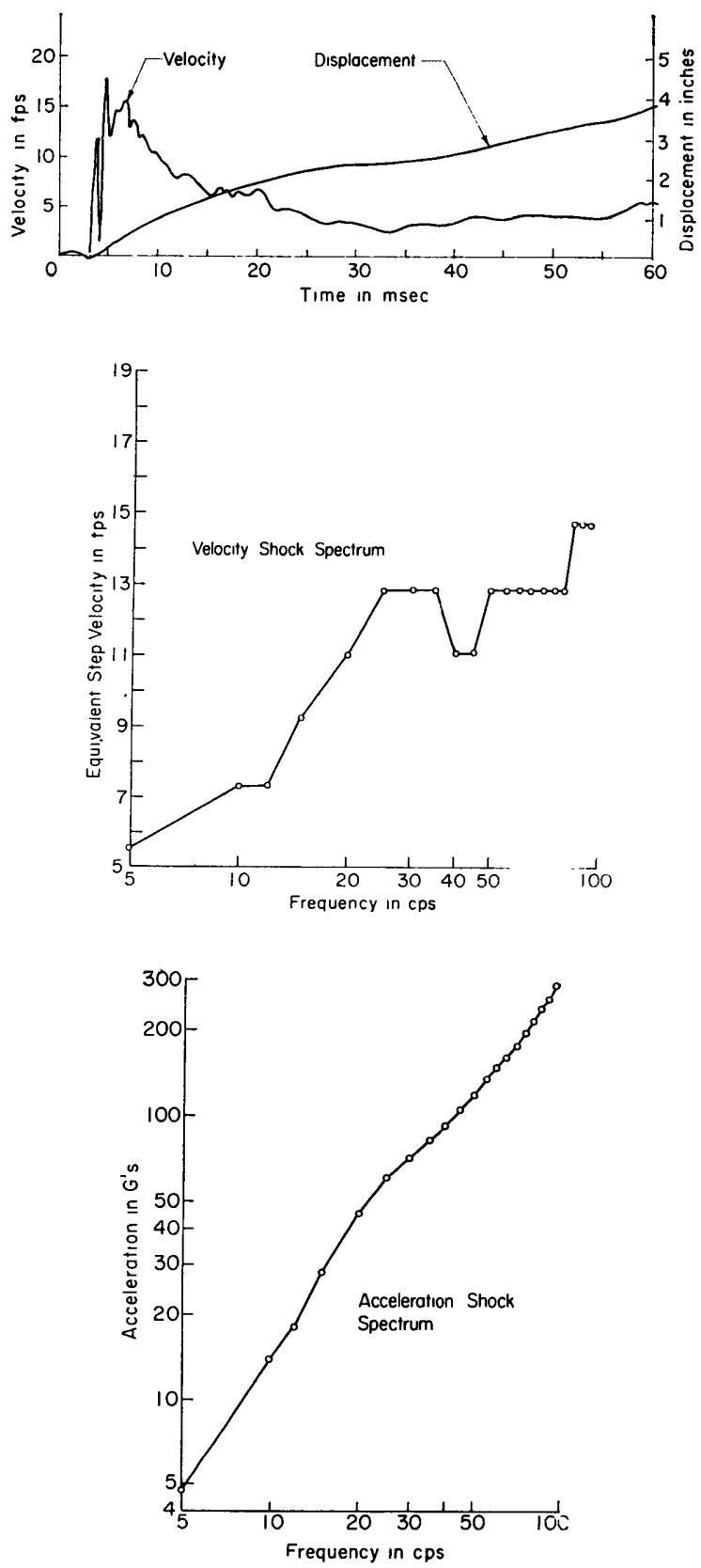

Fig. 40 Typical shock motion history and corresponding shock spectra (from a Liberty ship test)

in that for attacks with increasing severity, the velocity stays positive much longer than anticipated. Translated to the shock spectra it is obvious that the low-frequency end of the shock spectra is affected more than the high-frequency end.

This effect on the low frequency of the shock spectrum is further modified by the presence of
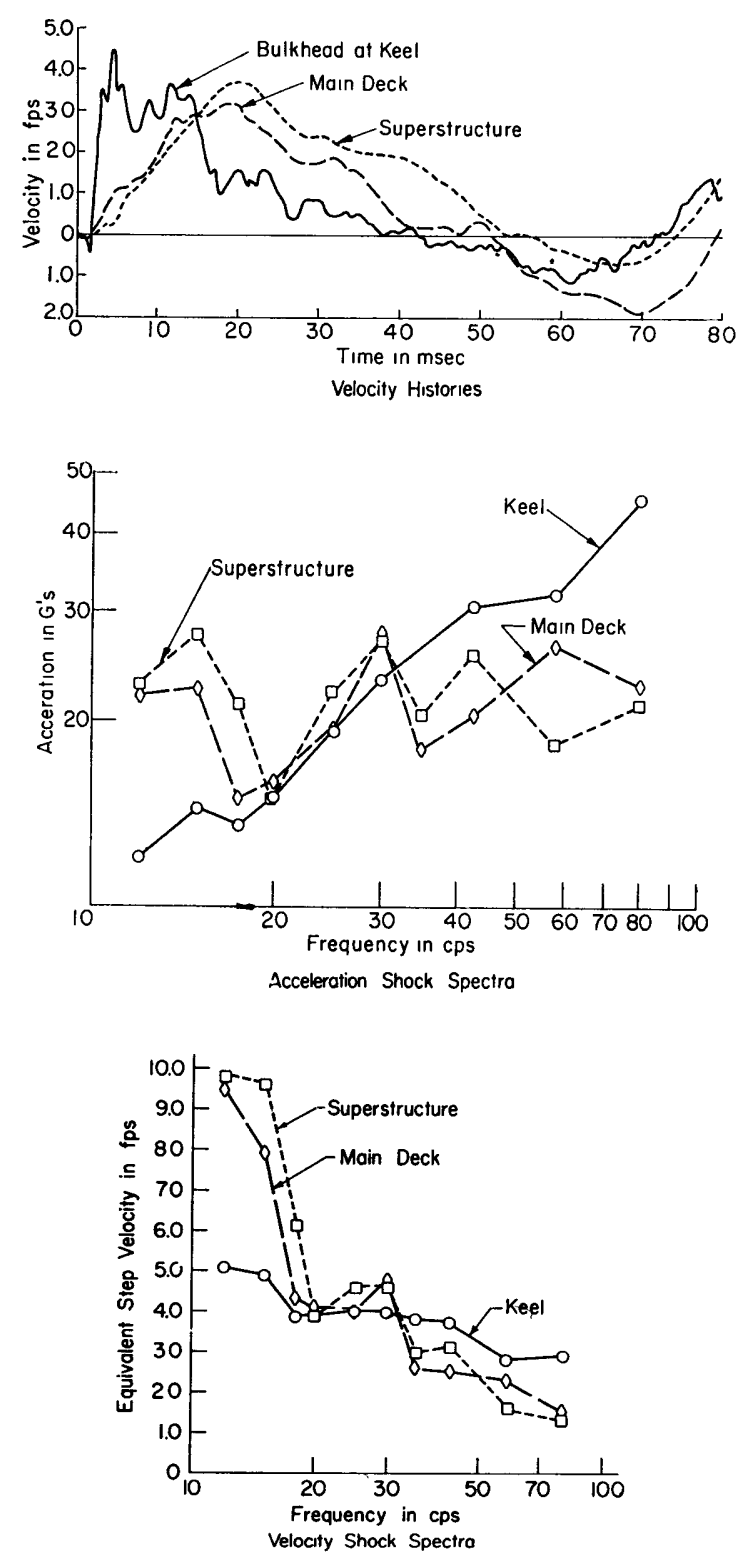

Fig. 41 Variation of shock environment throughout a destroyer (for moderate shock)

low-frequency motions due to the low-frequency natural vibrations of the upper decks (usually 15 to $20 \mathrm{cps}$ ) and those due to the rigid-body motion and the whipping of the ship's girder. The latter frequencies are of the order of 0.8 to $1.3 \mathrm{cps}$ for the forced rigid-body motion in case of mines and similar weapons, and about 1 to 5 cps for the beamvibration modes of interest. Their associated amplitudes throughout the ship vary drastically with region of attack and attack geometry. An inclusion of these effects in the generalized shock velocities is therefore not possible. 


\section{Ship Strengthening Against Underwater Explosions}

\section{Steps Toward Generalization}

The types of damage to ship hulls and to shipboard installations have been demonstrated. Efforts toward increasing the resistance of a ship against such attacks are not necessarily aimed at preventing plastic deformation but at preventing or reducing deformation of the structural elements and shipboard installations that are essential for the operational characteristic of the ship. Attention must therefore be given to preventing failures of vital equipment even for very severe attacks and to minimizing the effect of attacks on the structural seaworthiness of the ship. To develop such measures requires a knowledge of the damage pattern associated with various attacks and an understanding of the mechanism which brought about this damage. The analysis of the various response phases in the preceding parts of this paper has demonstrated that there is no general theory of ship response and of damage mechanism. It therefore becomes apparent that the dynamic response to the transient loads must be studied in phases and that experiments are required to check the validity and limitations of theoretical treatment.

The key problem in the study of the response of ship structures to explosive loading is how to reconcile the complexity of the actual naval architectural problems with what can be accomplished by theory. It is well known that the theoretical treatment makes it necessary to construct mathematical models of the structure, simplifying not only the explosive loading but also the structure and its response in the plastic range. How can the basic understanding gained from such theories and associated controlled laboratory experiments, which is necessarily limited to simple structures, be applied to the dynamic deformation of complex naval structures? Or, looking at the problem differently: How can the dynamic response of naval structures be broken down into the response of simple structural elements which lend themselves to theoretical treatment?

The need for testing of actual complex structures under realistic loads is apparent. Resort is taken to testing of structural models with all linear dimensions scaled by the scale factor. This eliminates or at least greatly reduces the need for conducting damaging tests with actual ship structures. It is known that such tests lead to dependable results of the response for static loads. It is probably less well known that the dynamic performance of ship structures far into the plastic range, resulting from explosion attack, can be reproduced exceptionally well with such realistic models under properly simulated or scaled loading conditions. The time factor which enters the scaling considerations does not lead to the familiar Froude scaling used so widely in hydrodynamics. The linear dimensions of the explosive charge and the attack geometries are scaled by the same linear scale factor as the structural model. Velocities, pressures, and stresses thus become the same for model and prototype, whereas the time is scaled linearly by the same factor as all geometric dimensions.

Naturally, many questions cannot be answered by model tests, especially those related to specific welding details such as heat-affected zones, certain fatigue aspects, and notch sensitivity. Careful attention in the use of models for explosion-effect studies is also necessary in those cases where gravity effects become important as, for instance, in the migration and later bubble pulse loadings. These effects do not obey the same scaling law and can lead to very pronounced differences in the damage to model and prototype because of differences in the later loading phases.

The previously described scaling, however, gives a good picture even for those structures where successive transmissions of loads occur as a result of excessive plastic deformation and rupture of those structural members that are loaded first. In these cases the variation of the ductility and notch sensitivity with plate thickness for otherwise identical materials enters the picture. The gross result is that models are relatively stronger than the prototype, since thinner plates can stretch more before tearing and have a somewhat higher dynamic strength. This, however, does not invalidate model tests for such structures, because this deviation can be taken care of by experimentally determined correction factors.

It is thus apparent that model studies are one of the tools, and perhaps the most important one, to effect the breakdown of complex structures into simpler ones in this study of dynamic deformations of naval structures under the complex explosion loads. They are especially helpful in determining which structural elements are important, how these elements affect the damage patterns, and which elements lend themselves to more rigorous theoretical analysis. Model tests, however, are not only essential in bridging the gap between the accomplishments of theory and the application of these results to naval structures but they are also instrumental in determining economically the effectiveness of structural changes, rearrangements, and design improvements for increasing the resistance to under water explosion attack. 
Naturally, ship tests are required on occasions to verify the validity of conclusions drawn from model tests. They are also needed to investigate the performance of equipment, machinery, and weapon systems aboard ships, as well as those features of the structural response which can not be studied on models.

The insight and experience gained from such studies of the ship response to underwater explosions serve two practical purposes. The understanding of the ship response in its relation to the attack parameters makes it possible to generalize the rather limited information on ship impairments gained from controlled tests to other conditions, thus establishing isodamage curves. Such generalizations are important for many naval applications. The understanding of the development of specific damage in the ship's structure and shipboard installations leads to concepts and methods for improving the resistance of ships to such attacks.

\section{Application to Hull Design}

A naval architect usually designs the hull structure in such a manner that for all expected load conditions the stresses are well below the yield point so that the structure will not deform permanently and will not suffer fatigue failures. To design hull protection on that basis is impossible. On the other hand, a certain amount of damage can often be accepted without impairing the operability of the ship. The logical choice in design for explosion resistance is to realize that large plastic deformation may occur.

The studies of variation of hull damage with standoff from an explosion show that light deformation of hull plating occurs at distances much greater than the standoff which corresponds to severe hull splitting. The major design effort is, therefore, not only to reduce the degree of deformation but, above all, to prevent hull rupture until the structure has experienced very large deformation. The structure, therefore, must be designed so that it can deform to a large extent, without rupture, by yielding in such a manner that it continues to offer the most resistance even as it deforms.

In just a few cases definite requirements are given and met to protect a ship against specific types and severities.of attack. A typical example is the torpedo protection system of capital ships designed to prevent flooding of critical spaces if subjected to the explosion of a torpedo [9].

In general; the naval architect will be satisfied to incorporate as much resistance against the explosion loads and the shock into the ship as practically feasible. The main effort will, therefore, be to eliminate features which are inherently detrimental and to incorporate additional bene ficial features. Several general conclusions are obvious:

(a) The designer must visualize the possible types and severities of deformations that may occur in the ship's structure, since the first step toward increased resistance of ships to underwater explosions must be made during the early design stages.

(b) The use of high-strength ductile steels is of advantage, whereas brittle hull materials are most dangerous.

(c) Extreme attention to detail design is necessary to prevent rupture at small over-all deformations due to stress concentrations and hard spots. Such features as backing strips, doubler plates, and so on, can reduce the severity of stress concentrations and thus permit maximum energy absorption by maximum plastic deformation without premature rupture.

(d) Proper compartmentation of the ship is necessary to prevent a large extent of flooding; also proper attention to bulkheads is necessary so that hull deformation does not lead to tears in the bulkhead near the shell.

(e) Any increase in girder strength is beneficial not only for structural seaworthiness but also for reducing the probability of girder failure due to whipping. Abrupt discontinuities in the ship's girder should be avoided.

(f) Sufficient clearance between machinery and installation and the hull itself is necessary to prevent puncturing of the deforming hull under impact with such installations.

\section{Applications to Shock-Hardening of Shipboard Systems}

The crippling of a ship, or its loss, is not necessarily caused by hull damage or loss of watertight integrity. It can also be caused by shock damage to vital machinery and installations With the increasing complexity of shipboard systems and the interrelation between systems, failures in minor components can become most serious.

Shock damage in ships occurs for attack severities much milder than those required to produce serious hull damage. The design of shipboard installations against shock is, therefore, just as important as the design for hull resistance. The most significant types of shock damage are as follows:

(a) Mutual impact of components of different systems which would have elastic responses if 


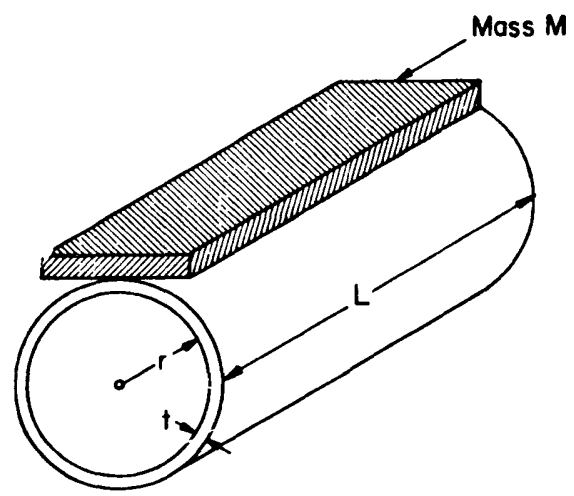

Cylinder

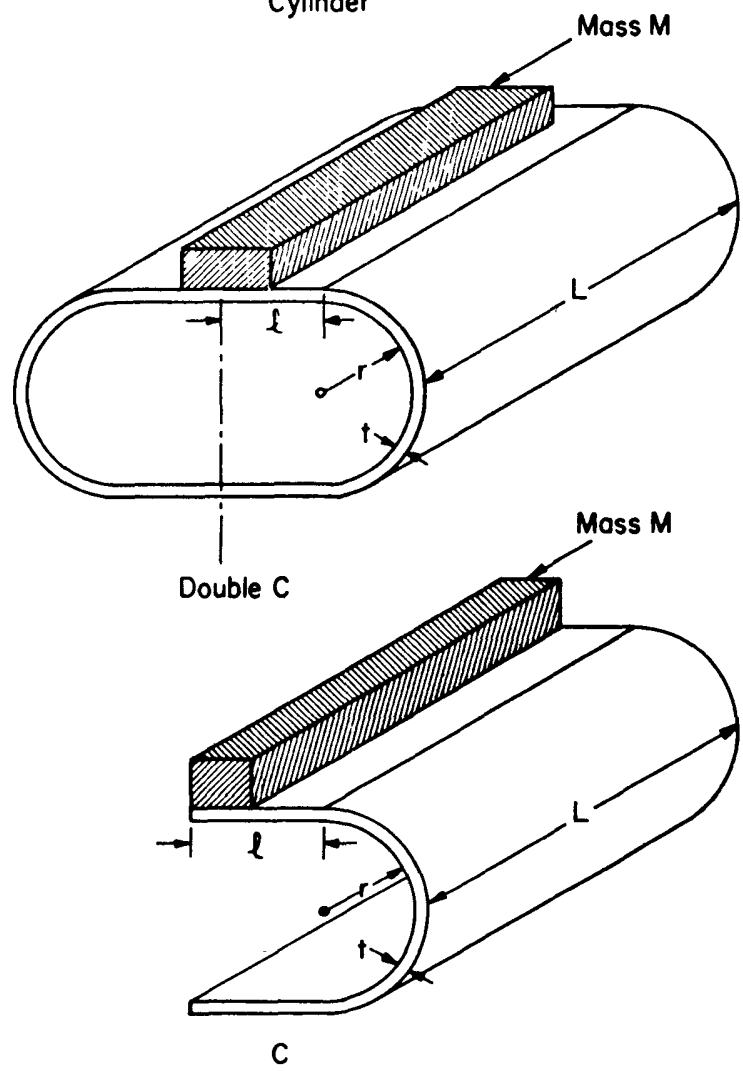

Fig. 42 Examples of yielding shock mounts

sufficient clearance were provided, or impact of a piece of equipment with the deforming hull.

(b) Failure of connections between separate shipboard installations because insufficient flexibility is provided in the "link" to survive the relative motions.

(c) Ejection of insufficiently secured subcomponents (vacuum tubes).

(d) Fracture of brittle materials, such as cast iron used in construction.

(e) Excessive amplitudes excited due to resonance. (f) Deformation of foundations and components due to yielding.

(g) Deformation of foundation and components due to buckling.

(h) Derangement due to deformation of supporting basic ship structure.

Any method used for assuring proper performance of machinery and equipment under shipboard shock requires:

(a) Establishment of a goal (definition of the shock environment which has to be survived).

(b) Translation of the goal into required levels or inputs for specifications. The specifications can specify, for instance, how to design for this level; or how to check a design to determine whether the system stays elastic under the required input; or how to shock-test a piece of equipment in order to determine whether it is acceptable under the specifications.

In any design consideration relative to shipboard shock, complications are introduced in the response analysis, for any attempts of a "rigorous treatment" under a given shock environment, by the following:

(a) The dynamic response of equipment and foundations which requires consideration of dynamic properties of materials.

(b) The built-in stresses which cause deviation from the otherwise "linear undamped system" for even small relative displacements.

The first step toward design against shipboard shock is the realization, by the designer, of what the shipboard shock environment is. This realization will automatically lead to "common-sense steps" to eliminate many of the failures described under shock damage $(a)$ through (e).

Protection against shock damage can be accomplished by steps which fall into at least one of the following categories. In all cases, either a theoretical (design) approach is made or the experimental approach of proof testing is used.

(a) The attentuation of the shock wave before it reaches the ship. A method used effectively for protection of turbines in dams when blasting in a reservoir is the creation of an extensive air-bubble curtain in the water between the duct entrance to the turbine and the place of the explosion [22].

(b) The resilient mounting of equipment and machinery on damped elastic mounts. In this case it is necessary to make sure that:

1 The shock transmitted initially is adequately reduced to an acceptable level, and that:

2 Resonances and/or bottoming of the 
mounts will not occur for the specified shock environment.

In these two cases it is necessary either to construct a mathematical model and to subject it to a group of shock velocities considered to be typical for the environment chosen as a goal, or to proof-test.

(c) The "accept plastic deformation" design. This concept accepts plastic deformation of supporting members. For instance, for a complicated piece of electronic equipment, misalignment is acceptable if sufficient flexibility in the connecting leads is provided and if sufficient clearance is available. The design is based on the maximum load which should be transmitted. Examples for this extremely attractive but seldom used concept are the designs described by Elmer [23], Fig. 42. These designs also offer great advantages if the supporting basic ship structure suffers local deformations.

(d) The "stay-elastic" design. In this category foundations and/or equipment are designed to stay clearly in the elastic range and neither yielding nor buckling is permitted for a specified shock input. For example, most foundations for machinery which requires alignment, as well as holddown bolts, are in this category.

The simplest design method used is the one that specifies a "static over design" by requiring that subbases, holddown bolts, feet, and so forth, are designed for $N$ times $\bar{W}(\bar{W}=$ the weight of equipment) instead of for supporting and holding $\vec{W}$. This "design number" $N$ will reduce with increasing $\bar{W}$, and will also depend on where this weight is installed aboard the ship.

The specific "design curves" are the result of much experience and testing. The design acceleration should not be confused with the actual maximum input accelerations measured during shock tests of the severity corresponding to the established shock design goal; since the latter are higher than the static design numbers. Application of this method in the design assumes implicitly that the maximum load for a piece of equipment of given total weight is the same for any equipment or piece of machinery, and for any type of installation. For "usual" foundation designs and "usual" machinery components and auxiliaries, such as pumps, motor, and so on, this is an acceptable assumption, since experience for such equipment is available. Application of the method becomes increasingly unreliable if applied to installation of "unusual" machinery. It is not applicable for equipment installed on resilient mounts.

"Dynamic design methods" can be based on critical input motions of significant structural
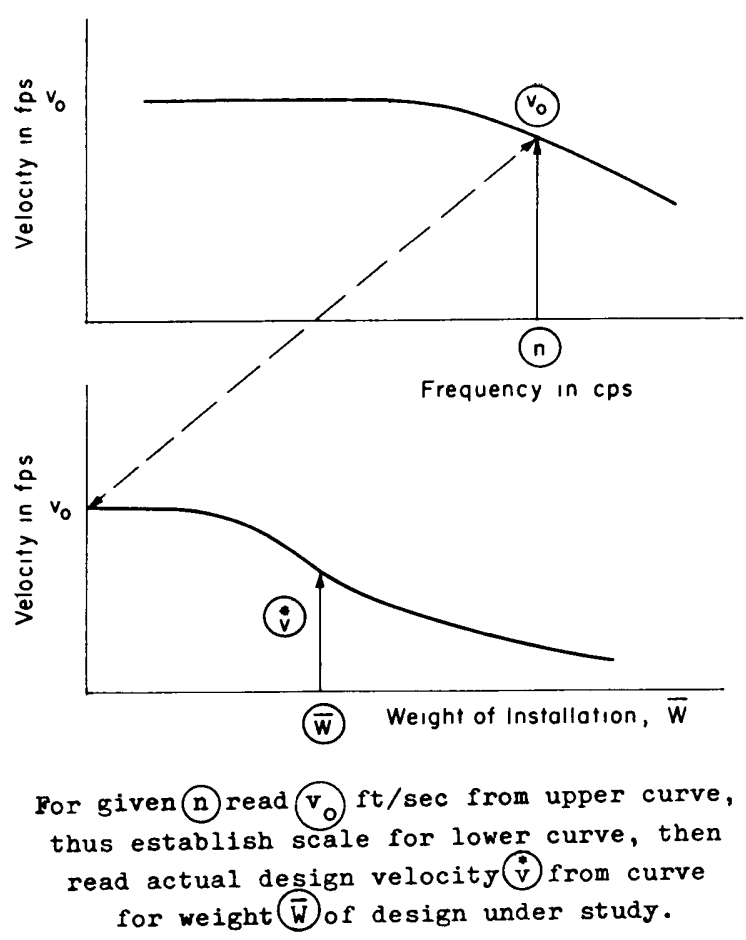

Fig. 43 Example of a possible design spectrum

elements or on extrapolations obtained from experimental results by an analysis of the dynamic response. The method proposed by Belsheim [24] assumes that the shock-spectrum velocity for any piece of equipment or installation for the natural modes of vibration of this system can be specified as a function of the total weight of the installation and of the frequency. Fig. 43 shows an example of a possible design spectrum.

It is emphasized that the design shock spectrum is not related to a specific actually observed, velocity history, since it describes the response of a linear system for a limited range of frequencies only. It is also important that the design shock spectrum is not the same as the shock spectrum derived from a direct analysis of a velocity record. This directly derived shock spectrum gives the response of a weightless linear system which does not affect the input motion. The actual input motion, however, had already been modified by the presence of the elastic systems (that is, the piece of machinery, for instance, coupled with a somewhat resilient hull), and the design shock spectrum takes this into account. The difficulty in the application of this method is the breakdown of the installations into a series of coupled elastic systems and the determination of the various frequencies. The method is definitely not applicable for very low-frequency 
systems and for installations on resilient mounts.

The actual accomplishment of shock hardening or shock toughness is demonstrated by shock tests. The equipment can be installed either on the anvil of a shock machine or in a ship. The U.S. Navy usually specifies that equipment weighing less than $4500 \mathrm{lb}$ must be shock-tested and must survive specified severities, since present shock machines are limited to equipment of less than $4500 \mathrm{lb}$. A special "floating shock platform" was developed to permit shock-testing of heavier equipment in the weight range up to $30,000 \mathrm{lb}$.

With the increasing complexity of shipboard installations and their interdependence, it is most important to assure proper shock strength of vital installations.

\section{Conclusions}

Many decisive improvements in the performance of ships attacked by underwater weapons can be made at little cost, if the designer tamiliarizes himself with the problems and visualizes possible deformations and the severity of shock motions. Such improvements are the responsibility not only of designers and builders of naval vessels built to fight the war at sea, but also of designers and builders of merchant ships. They face the same responsibility because the outcome of a future war may well depend to a great extent on the reliable performance of our merchant fleet in a wartime environment.

\section{Acknowledgments}

In the preparation of this paper the author depended heavily on results developed under the Bureau of Ships research and development program. He has made extensive use of the accomplishments of the Structural Mechanics Laboratory of the David Taylor Model Basin and the Underwater Explosions Research Division at the Norfolk Naval Shipyard. It is, however, impossible to give proper credit individually to the many staff members who have devoted their efforts for more than a decade to this field.

The author is indebted to Capt. J. A. Obermeyer, USN, Commanding Officer and Director, David Taylor Model Basin, and Prof. Harvey Evans for encouraging the preparation of this paper. He is further indebted to Capt. E. S. Arentzen, USN, and Professor Evans, Massachusetts Institute of Technology, for making it possible for the author to lecture on this subject at the Massachusetts Institute of Technology under the sponsorship of the Department of Naval Architecture and Marine Engineering.
This paper has been developed from these lecture notes.

He expresses his appreciation to the Model Basin staîf for their enthusiastic help in preparing this paper and for many helpful discussions, and to the authorities at the David Taylor Model Basin and the Bureau of Ships for permitting the use of the background material.

\section{References}

1 H. L. Abbott, "Report Upon Experiments and Investigations to Develop a System of Submarine Mines for Defending the Harbors of the United States," Professional Papers of the Corps of Engineers, No. 23, 1881.

2 C. Ramsauer, "Die Massenbewegung des Wassers bei Unterwasser Explosionen," Annalen der Physik, vol. 72, 1923, pp. 265-284.

3 H. Lamb, "The Early Stages of a Submarine Explosion," Philosophical Magazine, vol. 45, 1923, pp. 257-265.

4 S. Butterworth, "Report on the Theoretical Shape of the Pressure-Time Curve and on the Growth of the Gas Bubble," Compendium on Underwater Explosions Research, vol. 1, Office of Naval Research, 1950.

5 H. W. Hilliar, "Experiments on the Pressure Wave Thrown Out by Submarine Explosions," Compendium on Underwater Explosions Research, vol. 1, Office of Naval Research, 1950.

6 Compendium on Underwater Explosions Research, vols. 1, 2, and 3, Office of Naval Research, 1950.

7 R. H. Cole, "Underwater Explosions," Princeton University Press, Princeton, N. J., 1948.

8 S. Gladstone, "The Effects of Nuclear Weapons," U. S. Government Printing Office, 1957.

9 R. W. King, "Modern Weapons and Ship Protection," paper presented to the Chesapeake Section, SNAME, February 1959.

10 R. S. Hollyer, "Direct Shock-Wave Damage to Merchant Ships from Noncontact Underwater Explosions," paper presented to Hampton Roads Section, SNAME, April 1959.

11 H. G. Snay, "Unterwasser Explosions, Hydromechanische Vorgaenge und Wirkungen," Jahrbuch der Schiffbau Technischen Gessellschaft, vol. 51, 1957.

12 H. G. Snay, "Hydrodynamics of Underwater Explosions," Symposium on Naval Hydrodynamics, Publication 515, National Academy of Sciences.

13 A. Keil and W. Wunderlich, "Oscillation of Gas Globes in Underwater Explosions," Taylor Model Basin Translation 209, October 1947. 
14 Conyers Herring, "Theory of the Pulsation of the Gas Bubble Produced by an Underwater Explosion," Compendium on Lnderwater Explosions Research, reference [6], vol. 2.

15 H. M. Schauer, "The After Flow Theory of the Reloading of Air-Backed Plates at Underwater Explosions," Proceedings of First U. S. National Congress of Applied Mechanics, Chicago, I11., 1951, pp. 887-892.

16 A. N. Gleyzal, "Plastic Deformation of and Absorption of Energy by Thin Circular Plates Under Normal Loading," Underwater Explosion Research, vol. 3, Office of Naval Research, 1950.

17 A. H. Keil, "Problems of Plasticity in Naval Structures, Explosive and Impact Loading," Plasticity, Proceedings of the Second Symposium on Naval Structural Mechanics, Pergamon Press, New York, N. Y., 1960.

18 Wah and DeHart, "Study of the Response of a Ship to Shock Loading," to be published in Journal of Ship Research.

19 George Chertock, "The Flexural Response of a Submerged Solid to a Pulsating Gas Bubble," Journal of Applied Physics, vol. 24, 1953, pp. 192197.

20 T. P. Walsh and R. E. Blake, "The Equivalent Static Accelerations of Shock Motions," Proceedings of The Society of Experimental Stress Analysis, vol. 6, 1948, p. 150.

$21 \mathrm{H}$. H. Bleich, "Dynamic Interaction Between Structures and Fluid," Structural Mechanics, Proceedings of the First Symposium on Naval Structural Mechanics, Pergamon Press, New York, N. Y., 1960.

22 "Miraculous Bubbles," Compressed Air Magazine, August 1954.

23. G. D. Elmer, "Design Formulas for Yielding Shock Mounts," David Taylor Model Basin Report 1287, January 1959.

24 R. O. Belsheim and G. T. O'Hara, "Shock Design of Shipboard Equipment," Part 1, "Dynamic Design Analysis Method," NRL Report 5545, September 1960.

\section{Appendix 1}

The theory of the gas-bubble pulsation can be derived in a good-approximation with the assumption of an adiabatic gas expansion and contraction in an incompressible fluid; $[13,14]$. The initial energy radiated as a shock wave is considered a loss for the gas bubble, leaving for the start of the pulsation a spherical bubble with radius $r_{0}\left(r_{0}=\right.$ radius of explosive charge $)$ filled with a gas of pressure $P_{0}$ and a specific heat ratio

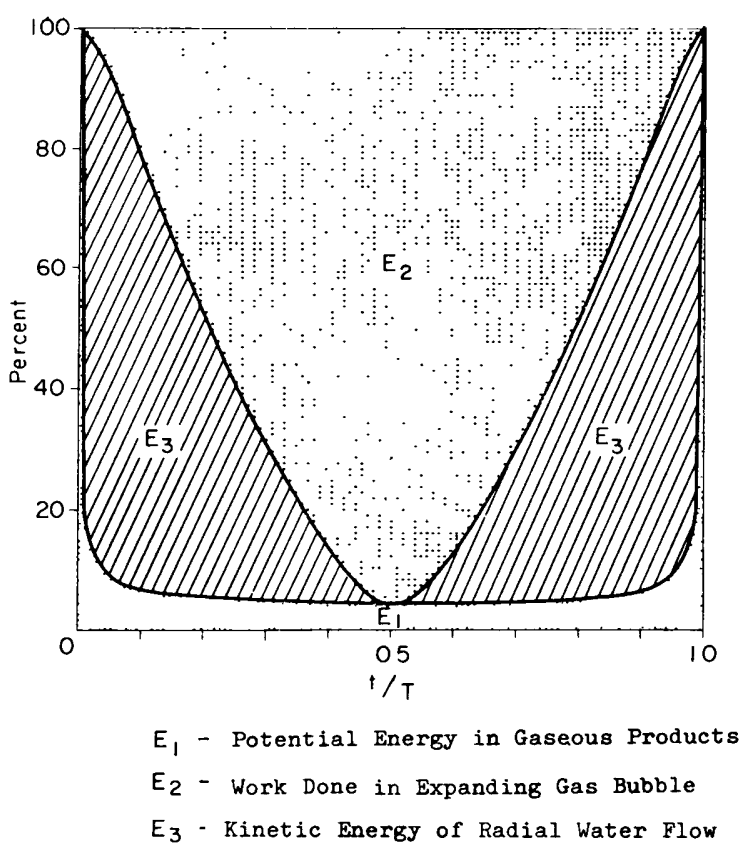

Fig. 44 Energy balance of first bubble pulsation

$c_{p} / c_{v}=K$. The hydrostatic pressure at the original location of the explosive was $p_{0}$. The equation for the bubble radius, then, is from hydrodynamic considerations:

$$
r \frac{d^{2} r}{d t^{2}}+\frac{3}{2}\left(\frac{d r}{d t}\right)^{2}+\frac{p_{0}}{\rho}=\frac{P_{0}}{\rho}\left(\frac{r_{0}}{r}\right)^{3 K}
$$

It is enlightening to consider the first integral of this differential equation, which can also be derived directly from the energy balance for the process. Three types of energy are in interplay:

Potential energy in gaseous products

$$
E_{1}=\frac{4 \pi P_{0}}{3(K-1)} r^{3}\left(\frac{r_{0}}{r}\right)^{3 K}
$$

Work done in expanding gas bubble

$$
E_{2}=\frac{4 \pi}{3}\left({ }^{3}-r_{0}^{3}\right) p_{c}
$$

Kinetic energy of radial water flow

$$
E_{3}=2 \pi \rho r^{3}\left(\frac{d r}{d t}\right)^{2}
$$

The energy balance requires that the sum of all three energies always equals the initial energy available in the gas globe, which gives

$$
\begin{aligned}
\frac{3}{2} \rho\left(\frac{d r}{d t}\right)^{2}=\frac{P_{0}}{K-1}\left\{\left(\begin{array}{c}
r_{0} \\
r
\end{array}\right)^{3}\right. & \left.-\left(\frac{r_{0}}{r}\right)^{3 K}\right\} \\
& +p_{0}\left\{\left(\frac{r_{0}}{r}\right)^{3}-1\right\}
\end{aligned}
$$




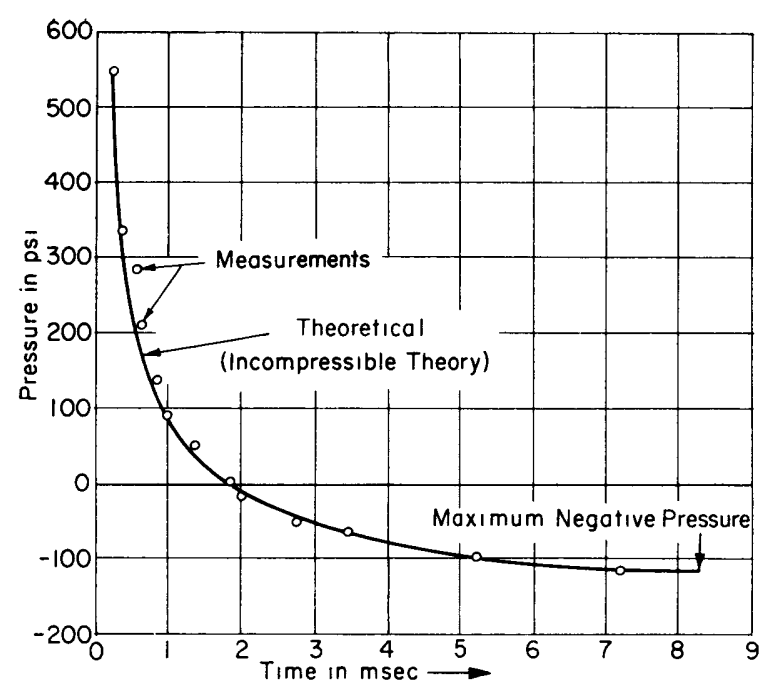

Fig. 45 Agreement between theoretical and observed pressure history of an underwater explosion

The three energy forms for the first pulsation are plotted schematically in Fig. 44. From the foregoing equation it follows that the radius history of the pulsation is given by

$$
t=\beta \int_{0}^{x} \frac{x^{z} d x}{\left[x-x^{4-3 K}+\alpha^{3}\left(x-x^{4}\right)\right]^{1 / 2}}
$$

with the abbreviation

$$
\begin{gathered}
x=\frac{r}{r_{0}} ; \beta=r_{0}\left[\frac{3(K-1) \rho}{2 P_{0}}\right]^{1 / 2} ; \\
\alpha=\left[\frac{(K-1) p_{0}}{P_{0}}\right]^{1 / 3}
\end{gathered}
$$

From this approach formula for $R_{\max }$ and $T_{1}$ can be derived

$$
\begin{gathered}
R_{\max }=r_{0}\left[\frac{P_{0}}{(K-1) p_{0}}\right]^{1 / 3} \\
T_{1}=1.49\left(\frac{3 \rho}{2}\right)^{1 / 2}\left(\frac{P_{0}}{K-1}\right)^{1 / 3} \frac{r_{0}}{p_{0}{ }^{5 / 6}}
\end{gathered}
$$

which have the pattern of the equations given previously. For $K=4 / 3$ an initial pressure of $P_{0}=130,000 \mathrm{psi}$ is derived for TNT. The actual agreement between the observed and this theoretical pulsation history has been proved by many investigators [13].

The bubble history obtained from this Appendix can be used to derive the pressure field in the water; that is, for the interval "after shock wave emission." The pressure deviation against the original hydrostatic pressure at a fixed location at distance $R$ from the explosion is

$$
\begin{aligned}
p(t)=\frac{\rho}{R}\left[2 r\left(\frac{d r}{d t}\right)^{2}+r^{2}\left(\frac{d^{2} r}{d t^{2}}\right)\right] & \\
& -\frac{\rho}{2}\left(\frac{r}{R}\right)^{4}\left(\frac{d r}{d t}\right)^{2}
\end{aligned}
$$

with $r$ as radius of the pulsating bubble. It is apparent that the first term in brackets [ ] indicates a $1 / R$ pressure variation just as an acoustic wave, and that the second term is associated with the incompressible flow which changes with $1 / R^{2}$ and thus represents the Bernoulli pressure. Naturally the propagation with sound velocity is not present, since the incompressible treatment leads to instantaneous propagation of pressure variation (infinite sound velocity).

The agreement between the pressure history thus derived and the pressure actually observed from an underwater explosion was pointed out by Schauer in 1949 and is shown in Fig. 45.

\section{Appendix 2}

\section{Exponential Shock Wave and} Unrestrained Plate

As a first step in the theoretical treatment, the interaction between a free, plane, unrestrained plate (water on one side, air on the other) and a plane underwater shock wave is considered.

In the interaction the simple acoustic treatment of the reflection is valid only up to the time when the pressure wave entering the steel plate has passed to the back of the plate. For a plate thickness of $1 \mathrm{in}$. this interval is 4 microsec, while the shock waves of interest have decay constants of 500 microsec and larger.

The total reaction of the plate is better described by considering a uniform velocity $r$ of the plate throughout its thickness. The incoming pressure wave $p(t)$ impinges on the plate; a reflected wave is initiated which, if the plate were peffectly rigid, would be equal to $p(t)$. Since the plate starts to move with a velocity $v(t)$, a "relief pressure" $\rho_{0} c_{0} v(t)$ is generated. The acting pressure on the plate is therefore

$$
2 p(t)-\rho_{0} c_{0} v(t)
$$

The acceleration of the plate must be equal to the acting pressure divided by the mass per unit area $\left(m=h \rho_{1}\right)$. Thus

$$
m \dot{v}(t)=2 p(t)-\rho_{0} c_{0} v(t)
$$

and for an exponential wave $p_{0} e^{-\theta / t}$, the solution is

$$
v(t)=\frac{2 p_{0}}{\rho_{0} c_{0}} \frac{1}{Z-1}\left\{e^{-\frac{t}{z \theta}}-e^{-\frac{t}{\theta}}\right\}
$$

\section{)}


with

$$
Z=\frac{m}{\rho_{0} c_{0} \theta}
$$

This term can be interpreted as characteristic mass ratio, since $\rho_{0} c_{0} \theta$ is the water mass in a cylinder of unit area cross section and a length from the shock front to the point where the pressure dropped to $1 / e$.

A maximum velocity is reached for

$$
t^{*}=\theta \frac{Z}{Z-1} \ln Z=\lambda \theta
$$

and amounts to

$$
v_{\max }=\frac{2 p_{0}}{\rho_{0} c_{0}} Z^{z / 1-z}=\frac{2 p_{\mathrm{c}}}{\rho_{0} c_{0}} e^{-\lambda}=\mu p_{0}
$$

The kinetic energy imparted to the plate at that moment is

$$
E^{*}=\frac{2 p_{0}^{2} \theta}{\rho_{0} c_{0}} Z^{1+z / 1-z}
$$

The pressure at the moment when $v_{\max }$ is reached is zero at the plate surface, which leads to the onset of cavitation in the water.

Fig. 46 permits the determination of the maximum velocity and the cavitation time for a given shock wave. This treatment can be extended to cover oblique incidence of the shock wave [6].

This treatment of the water-backed plate under exponential shock-wave loading is very similar to the air-backed plate concept except that in this case the transmitted wave has to be added in the equation of motion. This wave is $p_{\mathrm{tr}}=$ $\left(\rho_{0} c_{0} v(t)\right.$ and the equation becomes

$$
m \dot{v}(t)=2 p_{\imath}-2 \rho_{0} c_{0} v(t)
$$

In this case the total loading at the side hit by the incident shock wave never becomes zero. Cavitation does not occur. The transmitted wave resembles the incident wave except for the initial portion which has been rounded off because the plate had to be accelerated. A water-backed plate is therefore essentially "transparent" to the shock wave (Fig. 19).

The total displacement of the plate due to passage of the shock wave equals the particle displacement in water caused by the same passage.

A shock wave hitting the plane side shell of a merchant ship will interact with the hull plating. As a first step, the hull plating is considered unstiffened, giving a cavitation time $t^{*}$, for armaximum velocity $v_{\max }$. In the case of a $1-\mathrm{msec}$ decay time for a $1 / 2$-in. hull plate, $Z=0.065$ and $t^{*}=0.3 \mathrm{msec}$. With a stiffener spacing of 36 in., diffraction time from a stiffener to midbay is

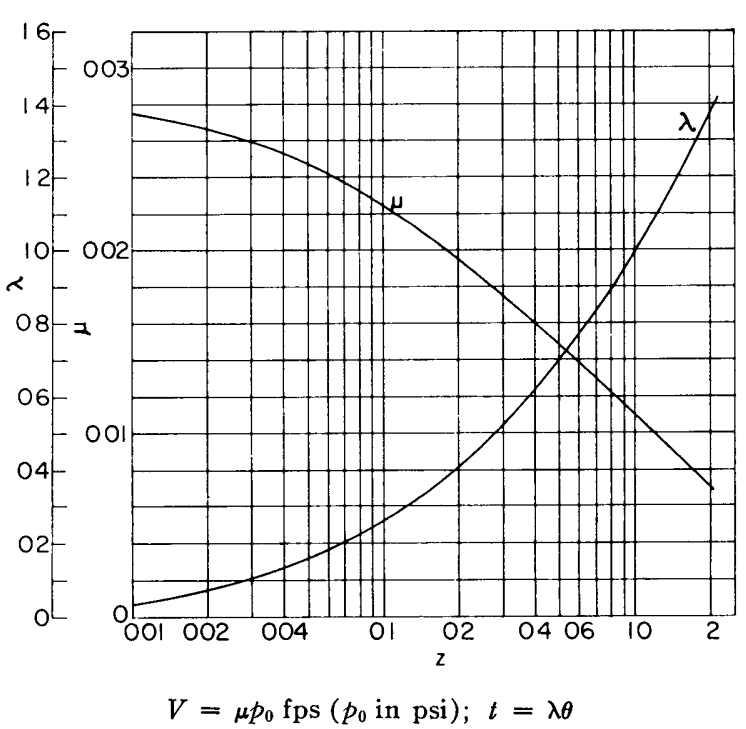

Fig. 46 Determination of maximum velocity and cavita. tion time for air-backed plate

also $0.3 \mathrm{msec}$. The stiffener's influence should, therefore, make itself, felt in the development of the plate velocity, while, on the other hand, the plate velocity will partly be used to accelerate the stiffeners and only partly to produce plate deformation between stiffeners. A common velocity for stiffener and plate will develop rapidly.

A shock wave hitting the plane side shell of a merchant ship under any angle of incidence therefore produces a kick-off velocity for the stiffened shell which can be calculated from previous formulas if the ratio, half the shortest plate dimension divided by sound velocity, is much larger than the calculated time for reaching kickoff velocity; that is, time for onset of cavitation. Since the damage patterns indicate that the deformation of the shell is a smooth contour from bulkhead to bulkhead and bottom to deck, if plate dishing between stiffeners is disregarded, the compartment length and height have to be used, and these ratios are then 2 to $3 \mathrm{msec}$. Kickoff, therefore, actually occurs for a $1000-1 \mathrm{~b}$ TN'T charge $\left(p_{0}=1600 \mathrm{psi}, \theta \sim 1 \mathrm{msec}\right)$ at about 0.3 msec. The initial velocity can therefore be calculated, based on the assumption that the stiffener is spread over the plate which results in an increase in plate thickness.

In general, the theory is applicable for the calculation of kickoff velocities as long as the time interval between shock-wave incidence and occurrence of the maximum velocity is small with respect to the diffraction time; that is, the time for propagation of a pressure signal from the restfain or edge of the panel to the plate center. 


\section{Appendix 3}

\section{Plastic Deformation of Plates and Membranes}

The simplest structural element in naval structures is the plate supported at its edges. Because of symmetry of construction the plate can be considered clamped at the edges. The simplest geometry is the circular plate; hence clamped circular air-backed plates were chosen during the war years for the first studies of plastic deformation of plates under static loads. Later the studies were extended to rectangular plates, and theories were developed for relating the maximum deflections, loads, plate dimensions, and material properties (for instance, reference [16]). The energy absorbed by plastic deformation of this circular plate (radius $a$, thickness $h$, center deflection $d_{c}$, yield stress $\sigma_{y}$ ) was derived. Bending was disregarded because of the large plastic over all deformation of the plate.

Assuming the simplest yield process $\left(\sigma_{\mathrm{rad} \text { al }}=\right.$ $\sigma_{\tan }=\sigma_{y}$ ) the work done by the acting pressure as the deformation develops is set equal to the energy absorbed in plastic deformation ( = area of deformed plate minus $a^{2} \pi$ times $h \sigma_{y}$ ). This leads for a spherical contour of the deformed plate, to the relation

$$
d_{c}=\frac{a^{2}}{4 h \sigma_{y}} p
$$

between center deflection $d_{c}$ and applied pressure $p$.

Both the center deflection and the absorbed energy of plastic deformation are of interest not only for circular clamped plates but also for rectangular and square plates. For the latter two, the half lengths of the sides are denoted $a_{1}$ and $a_{2}$ (square $a_{1}=a_{2}$ ). The results are summarized in Fig. 47.

The agreement of this simple treatment of the plastic deformation with experiments was shown by Gleyzal [16].

The rapidly changing explosion loads do not lead to a quasistatic plastic deformation but to a rapid deformation process which carries the material into the range of plastic deformation. The deflection contours of the deformed plate, which developed, are not necessarily the same as found in static loading [17].

It is apparent from the previous studies of the details of the damage mechanism that many simplifications are required in the treatment of the step-by-step response (dynamic plastic deformation contour differs from static deformation contour, dynamic yield is different from "static" yield, water mass moving with plate, reloading

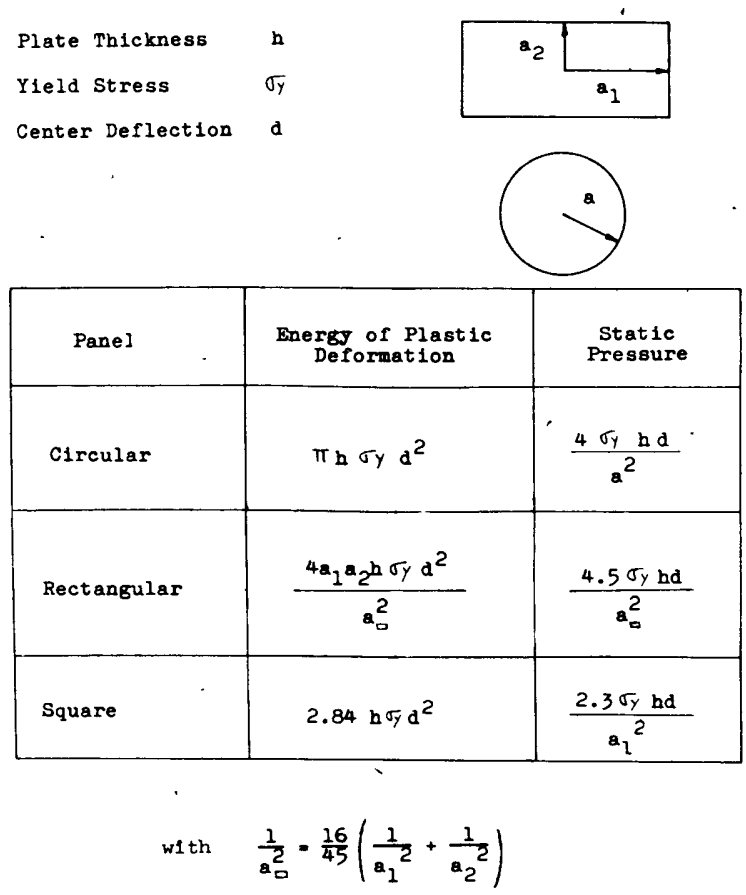

Fig. 47 Plastic deformation of clamped panels 'spherical contour of deformed plate)

mechanism, simplified treatment of yielding plate, and so on). It is obvious that a comparison of applied dynamic loads with the static load required to produce the same plastic deformation is not proper. Instead, the energy delivered into the structure and the energy of deformation have to be considered. It is tempting to use a gross treatment, considering as input energy the total shock-wave energy radiated toward the plate surface and relating this to the total energy absorbed in plastic deformation of the clamped plate.

The shock-wave energy density (including after flow) was given before as

$$
E_{\mathrm{sh}}=200 \mathrm{~W} / R^{2} \mathrm{ft}-\mathrm{lb} \text { per in. }{ }^{2}
$$

The energy of plastic deformation for a plane plate deformed to a spherical shape was

$$
\pi h \sigma_{y} d^{2}
$$

The energy balance provides

$$
\begin{gathered}
200 \frac{W}{R^{2}} \pi a^{2} \approx \pi h \sigma_{y} d^{2} \\
d \approx \frac{a}{\left(\sigma_{y} h\right)^{1 / 2}} \frac{W^{1 / 2}}{R}
\end{gathered}
$$

This functional relation between attack configuration and the plate characteristics agrees 


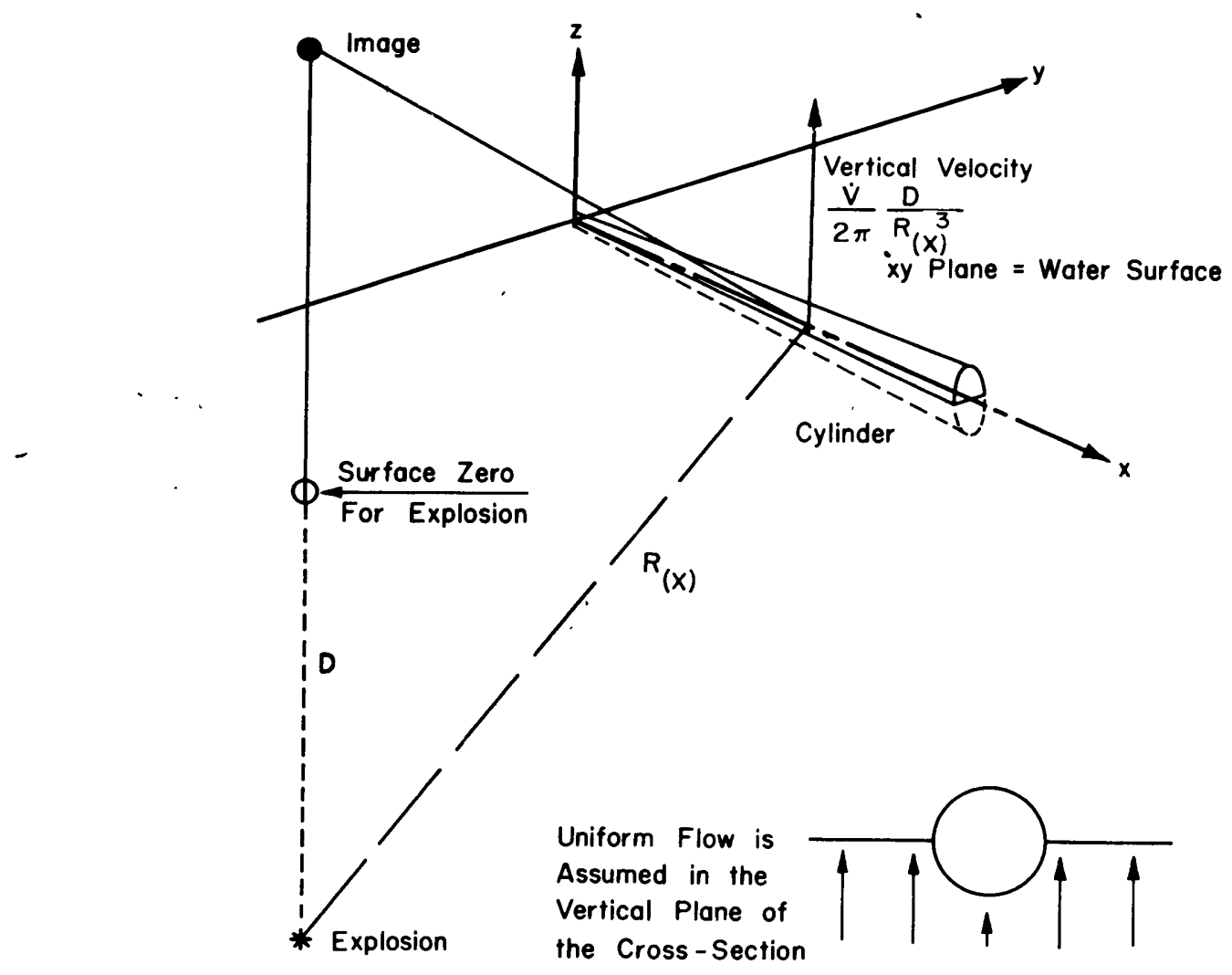

Fig. 48 Attack geometry

well with observations except for a numerical correction factor which takes care of all the other problems.

\section{Appendix 4}

Beam Response to Loading by Pressure Field of Gas Bubble

The theory of this response was advanced by Chertock [19]. It is based on the observation that the theory of the gas bubble in incompressible water gives a good description of the pressure history in the water and that it is therefore appropriate to apply this loading to the ship girder, especially since (except for the lack of a finite propagation velocity) this theory also provides for a rather good approximation of the shock-wave history. The treatment based on this theory naturally does not account for acoustic interactions but treats the case as an incompressible flow problem and neglects the differences in arrival time of the shock wave at the various ship sections.

To demonistrate the salient features of this theory, Murray's derivation of Chertock's results is followed. Consider a floating cylinder, half submerged, with a diameter small in comparison with the length. The length is considered short with respect to the standoff $R$, from the explosion which occurs at a depth $D$ (see attack geometry, Fig. 48). At any distance $R$, the explosion generates a radial free field flow velocity $V / 4 \pi R^{2}$, with $\dot{V}$ denoting the volume change of the gas bubble. The actual flow, however, is affected by the free surface. This effect can be taken into account by introducing a negative image of the explosion and leads to a flow velocity vertical to the water surface of

$$
\left(\frac{V}{2 \pi R^{2}}\right)\left(\frac{D}{R}\right)
$$

A cross section of the ship is then subjected to a time-variant flow. Because of the assumptions made in the beginning, the cross section can be considered subjected to a plane flow with this velocity, and the force exerted on this cross section of the cylinder (located at co-ordinate $x$ ) thus becomes

$$
f(x, t)=\frac{\rho A}{\pi} \frac{D}{R_{(x)}{ }^{3}} \frac{d^{2} V}{d t^{2}}-\rho A \frac{d^{2} z}{d t^{2}}
$$


This forcing function now has to be considered in the equation for the vibration of the ship's girder, which yields (assuming for simplicity a homogeneous beam)

$$
E T \frac{\partial^{4} Z}{\partial x^{4}}=-2 \rho A \frac{\partial^{2} Z}{\partial t^{2}}+\frac{\rho A}{\pi} \frac{D}{R_{(x)}{ }^{3}} \frac{d^{2} V}{d t^{2}}
$$

The solution of this equation is best handled by means of the normal modes $u_{i}(x)$ of vibration of the hull girder:

$$
Z(x, t)=\Sigma a_{i}(t) u_{i}(x)
$$

Based on the orthogonality conditions of the vibration patterns:

$$
\frac{d^{2} a_{i}}{d t^{2}}+\omega_{i}{ }^{2} a_{\imath}=\frac{1}{2 \pi} \frac{d^{2} V}{d t^{2}} \int_{0}^{L} \frac{D u_{i}(x)}{R_{(x)}{ }^{3}} d x=\frac{P_{i}}{2 \pi} \frac{d^{2} V}{d t^{2}}
$$

where $P_{2}$ is the "position factor." This yields the amplitudes for each mode

$$
a_{\imath}(t)=\frac{P_{\imath}}{2 \pi}-\omega_{i} \int_{0}^{t} \frac{P_{i}}{2 \pi} V(t) \sin \omega_{\imath}(t-\tau) \mathrm{d} \tau
$$

The amplitudes of the various bending modes and the heaving and the pitching can thus be determined by using a theoretical volume history of the bubble, Fig. 5, or by use of an experimentally established volume history, which describes not only the first but also the later pulsations. The superposition of the response in the various modes then gives the displacement history of the ship. Bending stresses at each location along the ship's girder are derived from the superposition of the curvatures of the various bending modes at their respective locations.

\section{Appendix 5}

\section{The Shock Spectrum}

Consider the linear system shown in Fig. 49, with mass $m$ on a spring with restoring force $-k x_{1} ; x_{1}$ is the displacement of the mass against the support. If the support is at rest;

$$
m \ddot{x}_{1}=k x_{1} \quad\left(\frac{k}{m}=(2 \pi n)^{2}=\omega^{2}\right)
$$

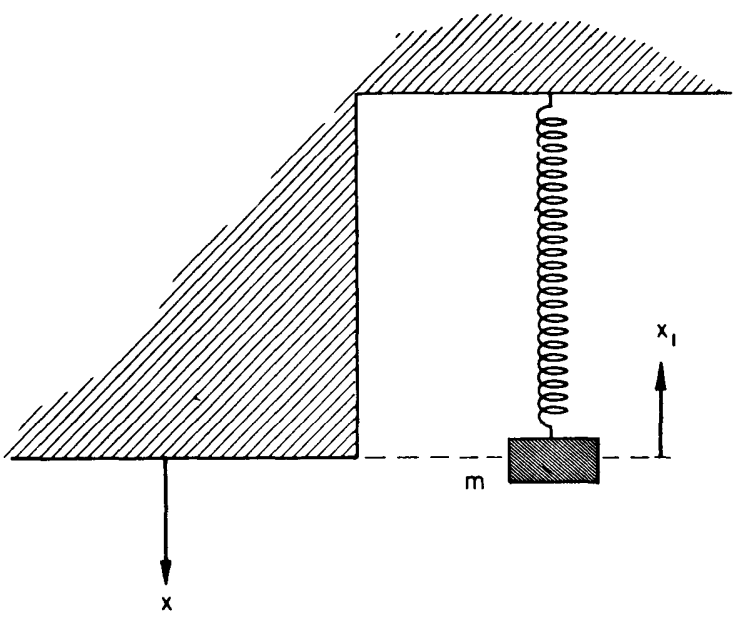

Fig. 49 Linear mass-spring system

Since the support moves with $\dot{x}=v(t)$

$$
\begin{gathered}
m\left(\ddot{x}+\ddot{x}_{1}\right)=-k x_{1} \\
\ddot{x}+\ddot{x}_{1}=-\omega^{2} x_{1}
\end{gathered}
$$

The shock response $x_{1}(\omega, t)$ is

$$
\begin{aligned}
x_{1}(\omega, t) & =-\frac{1}{\omega} \int_{0}^{t} \dot{v}(\tau) \sin \omega(t-\tau) d \tau \\
& =-\int_{0}^{t} v(\tau) \cos \omega(t-\tau) d \tau
\end{aligned}
$$

The maximum displacement for this system is thus

$$
\mathrm{d}(\omega)=\left|x_{1}(\omega, t)\right|_{\max }
$$

In the simplest case of a step velocity, increasing instantaneously from zero to $v_{0}$, the shock response of the linear system is

$$
x_{1}(\omega, t)=-\frac{\varepsilon_{0}}{\omega} \sin \omega t
$$

The maximum relative displacement is $\dot{d}=$ $v_{0} / \omega$; the maximum relative velocity is $v_{\mathrm{r}}$; the maximum absolute velocity is $2 v_{\mathrm{c}}$; the maximum acceleration is $v_{0} \omega$; and the maximum force on the spring is $k\left(v_{0} / \omega\right)=\omega v_{\mathrm{r}} m$. 


\section{INITIAL DISTRIBUTION}

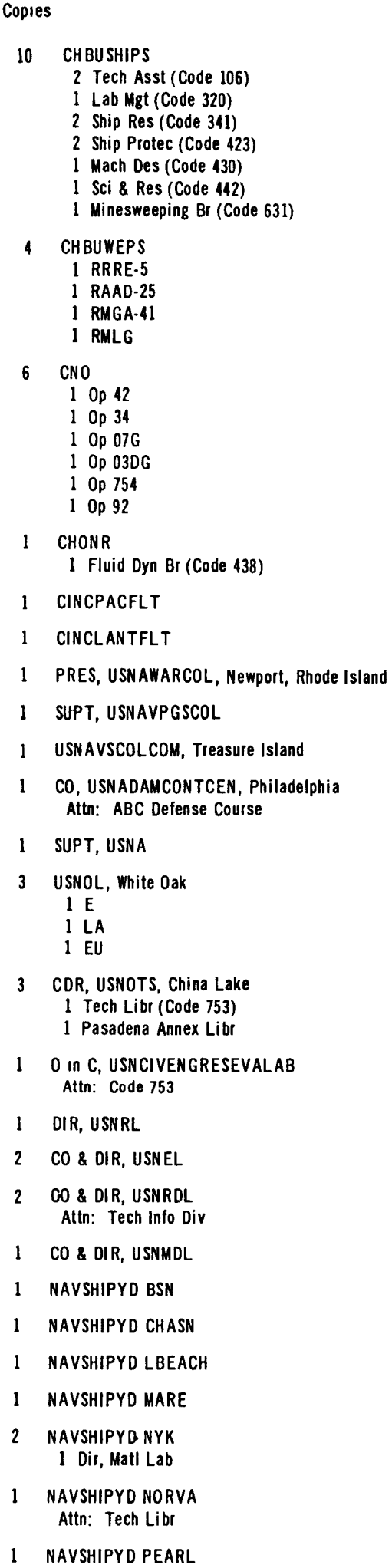

1 NAVSHIPYD PEARL

Copies

1 NAVSHIPYD PHILA

1 NAVSHIPYD PTSMH

1 NAVSHIPYD PUG

1 NAVSHIPYD SFRAN

1 CO, USNROTC \& NAVADMINU MIT

1 USNWEPLAB, Dahlgren Attn: Experimental officer

2 CO \& DIR, USNEES Attn: Tech Libr

1 CO, USNUOS

$2 C O \&$ DIR, USNUSL

2 CHOFEngrs, ENGIndiv Dept Army 1 ENGNB

1 ENGEB

1 CG, USCONTARMYCOM

1 Pres, Bd 4, Hdq CONARC, Ft Bliss, Texas

1 CG, ENGRESDEVLAB Attn: Chief, Tech Intelligence $\mathrm{Br}$

1 CO, PICATINNY ARSENAL, Dover, N. J. Attn: ORDBB-TK

1 CO, TRANSRESDEVCOM, Fort Eustis, Va. Attn: Special Projects Div

1 DIR, USWaterways Exper Sta Attn: Mr. J. Strange

1 CHOFORD, Dept of Army Attn: ORDTX-AR

1 DIRDEFRESDEV Attn: Tech Libr

1 US Documents Officer, SHAPE, APO 55, N.Y

1 DIR, WPNSYSEVALGRP, OSD

1 CDT, AFSTAFCOL, Norfolk Attn: Secretary

1 Luckenback Graduate School, Webb inst of Naval Arch via INM, Garden City, N.Y.

1 Natl Res Council Mıne Advisory Com

10 CDR, ASTIA

1 Univ of Calıf Attn: Prof H.A. Schade

1 Univ of Michigan Attn: Prof R.B. Couch

1 MIT Attn: Prof J.H. Evans

1 VPI Attn: Prof A.M. D'Arcangelo

1 Webb Inst of Tech Attn: Prof E.V. Lewis

1 Amherst College Attn: Dr. A.B. Arons

1 New York Univ Attn: Dr. G. Hudson
Copies

1 Harvey Mudd College Attn: Dr. A.B. Focke

1 Columbia Univ Attn: Dr. H.H. Bleich

1 Cambridge Acoustical Assn Attn: Dr. M.C. Junger

50 DTMB (UERD) (Code 780) 



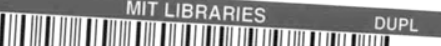

39080027544078 
